Brazilian Journal

of Chemical

Engineering

\title{
SUCROSE CRYSTALLIZATION: MODELING AND EVALUATION OF PRODUCTION RESPONSES TO TYPICAL PROCESS FLUCTUATIONS
}

\author{
Bruno J. C. de Castro ${ }^{1}$, Melécio Marciniuk Junior ${ }^{1}$, \\ Marco Giulietti (in memoriam) and André Bernardo ${ }^{1 *}$ \\ ${ }^{1}$ Universidade Federal de São Carlos, Departamento de Engenharia Química, São Carlos, SP, Brasil. \\ E-mail: bruno.chiaramonte@hotmail.com - ORCID: 0000-0003-0606-3224; meleciomjunior@gmail.com; \\ ORCID: 0000-0002-7883-5855; abernardo@ufscar.br - ORCID: 0000-0002-9345-3361
}

(Submitted: June 4, 2018 ; Revised: August 22, 2018 ; Accepted: September 28, 2018)

\begin{abstract}
This work describes a phenomenological model of the two-massecuite system for sucrose crystallization, developed using EMSO software. In most Brazilian sugarcane industries, sucrose crystallization is performed using this system. This process is considered to be a fundamental step in obtaining sugar of the desired quality and accounts for a substantial fraction of the production costs. The simulation results - crystal percentage in massecuite, brix and purity of molasses, magma purity, sugar pol, crystal size distribution - were validated by comparing them with real process data of an industrial plant. The interest of the phenomenological model to study the possible impacts of impurities and process instability was illustrated by varying the simulation inputs related with the syrup purity, syrup brix and steam conditions.

Keywords: Sucrose crystallization; Phenomenological modeling; Simulation; EMSO.
\end{abstract}

\section{INTRODUCTION}

Industrial sugar crystallization is an energy-intensive process that accounts for a significant fraction of the overall production costs (Shamim et al., 2016). Due to the importance of the crystallization step in determining the quality of the sugar produced, and the low level of automation found in sugarcane industries, efforts have been directed towards satisfactorily modeling it and developing control structures. There have been various studies of sucrose crystallization kinetics, using different approaches. Some have aimed at determining the kinetic parameters of crystallization from pure sucrose solutions, under different conditions of supersaturation and agitation (Howell et al., 2002; Khaddour et al., 2010; Van Hook, 1944). Others have studied the reduction of the crystal growth rate and the change in the crystal habit in the presence of impurities commonly found in the industrial process (Martins et al., 2005; Ouiazzane et al., 2008a; Van Hook, 1948, 1946).
Van Hook (1945) performed experiments that suggested that, under certain operating conditions, the crystal growth rate is controlled by the step involving molecule deposition into the crystal lattice, rather than by the transport of sucrose across the crystal-solution boundary. Liang and Hartel (1991) proposed a model for crystal growth in a continuous crystallizer that considered the growth rate dispersion (the occurrence of different growth rates among the crystals) due to random fluctuations during the process. Ouiazzane et al. (2008b) used a cooling batch process to determine the kinetic parameters of secondary nucleation and growth. Kumar et al. (2008) constructed and tested a neural network to analyze crystal growth under different operating conditions.

Studies concerning the modeling and simulation of the industrial process of sucrose crystallization can also be found in the literature. Chorão (1995) developed a phenomenological mathematical model to simulate crystallization, including the phenomena of nucleation,

\footnotetext{
* Corresponding author: André Bernardo - E-mail: abernardo@ufscar.br
} 
growth, and agglomeration. A sensor was developed to monitor process variables that are not easily measured, and experimental measurements were made of parameters related to the heat and mass transfer in the crystallizer. Georgieva et al. (2003) proposed a hybrid model for a sugar refining crystallizer, based on two modules, the first (phenomenological) containing the mass, energy, and population balances, and the second consisting of a neural network to estimate the kinetic parameters of nucleation, growth, and agglomeration.

Other works were concerned with integration of the crystallization process with the other steps of sugar production. Jesus (2004) modeled the multiple effect evaporation and the process of an industrial vacuum pan, comparing the simulation results with real process data. Mazaeda et al. (2014) described a model for optimization of a crystallizer in terms of its steam consumption, considering fluctuations of syrup flow rate, concentration, and purity. Shamim et al. (2016) also proposed a model for optimization of steam consumption, taking into consideration the preceding step of juice evaporation.

Beyond the practical interest in crystallization modeling, the adoption of models to describe this process is also of great scientific interest, since the fundamental mechanisms involved in crystallization are not yet fully understood (Georgieva et al., 2003). Additional difficulty is found in simulation of the twomassecuite crystallization system, which is widely used in Brazilian sugar industries that produce both sugar and ethanol, since there is still little reference to it in the literature (Chen and Chou, 1993; Dias et al., 2015; Gonzales and Andrade, 2018; Hugot, 1986). However, the development of a dynamic simulation of this industrial process, with molasses recycling, is necessary in order to test the effectiveness of possible control structures.

Therefore, the aim of this work was to develop a model of the two-massecuite crystallization process, using EMSO (Environment for Modeling, Simulation, and Optimization) simulation software. The model was based on the fundamental principles of mass and energy conservations, as well as the population balance, including the phenomena of nucleation and growth rate dispersion. The relations between operating conditions and sugar production responses were also studied by modifying the characteristics of the syrup and the steam, which were used as simulation inputs.

\section{MATERIAL AND METHODS}

Fig. 1 shows a flow diagram of the industrial two-massecuite sugar crystallization process model implemented using EMSO software. This simulator uses a modeling language with concepts of objectoriented programming, which allows the construction of complex models, for steady or transient states,

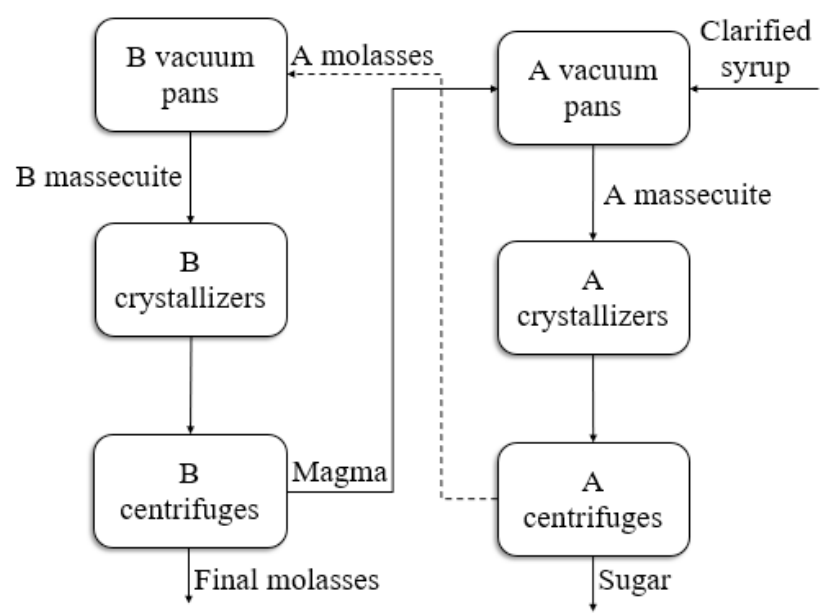

Figure 1. Flow diagram of the industrial twomassecuite sugar crystallization process.

from simpler models, using concepts of inheritance and composition (Rodrigues et al., 2010; Soares and Secchi, 2003, 2004).

The process of an industry located in São Paulo State was used as a basis for the modeling. In this process, a B vacuum pan was used for graining (seed growing). Seeds consist of a suspension of a known population of sucrose crystals in anhydrous ethanol. The following steps were performed in this vacuum pan: filling the calandria with the A molasses, concentration, graining, and total filling with the A molasses. The massecuite was then divided into three $\mathrm{B}$ vacuum pans, which were also filled with the A molasses, in procedures known as "cuts".

Throughout the whole process, the flow rates of molasses and steam in the filling steps were controlled to keep the supersaturation index within the metastable zone limits, so avoiding the dissolution of crystals or the secondary nucleation (Hugot, 1986; Mullin, 2001).

The volumes to be completed in each step were based on the B vacuum pans of the industry studied. They had a total usable volume of $65 \mathrm{~m}^{3}$, with calandria of $26 \mathrm{~m}^{3}$. After completing the volume of the three B vacuum pans, the following steps were performed: tightening in order to reach the desired crystal concentration, and discharging into the B crystallizers.

In the A vacuum pans, the calandria was filled with magma, which was the wet sugar from the B centrifuges. The following steps were then performed: concentration, total filling with clarified syrup, dividing the massecuite into two vacuum pans, filling of the two vacuum pans with clarified syrup, tightening, and discharging into the A crystallizers. The flow rates of syrup and steam during the filling steps were also such that, throughout the entire process, the supersaturation remained within the metastable zone limits. The A vacuum pans of the industry studied were used as references. They had a total usable volume of $40 \mathrm{~m}^{3}$, with calandria of $14 \mathrm{~m}^{3}$. Fig. 2 shows a schematic 


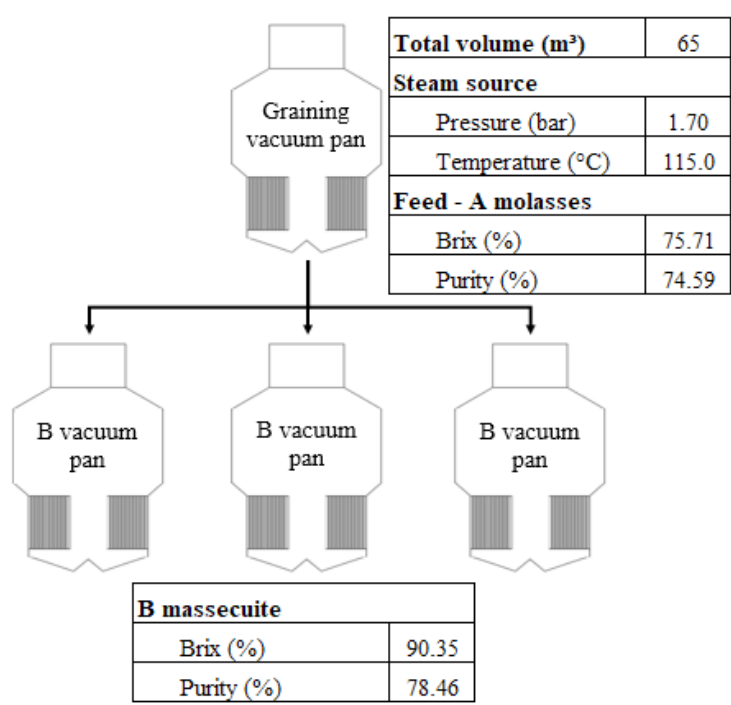

Figure 2. Schematic illustration of the A and B vacuum pans.

illustration of the A and B vacuum pans, along with information about their volume, steam source, feed and final massecuite.

In the base simulation, steam at 1.70 bar of absolute pressure and temperature of $115{ }^{\circ} \mathrm{C}$ was used. These conditions characterized the steam that was generated in the preceding juice evaporation step. The absolute pressure inside the pans was kept at 0.23 bar (vacuum of $22.7 \mathrm{inHg}$ ), which in practice was ensured using barometric condensers. The values used for the brix and purity of the clarified syrup used in the A vacuum pans were the averages of these variables obtained for the period between June 1 and October 31, 2015, in the studied industry: $58.27 \%$ and $85.92 \%$, respectively. The temperature of the clarified syrup was kept at $65{ }^{\circ} \mathrm{C}$, which is a typical value for this stream. The temperatures of the water added to the massecuite to control supersaturation and the water used to dilute the magma were considered to be $90{ }^{\circ} \mathrm{C}$. This was the temperature of the evaporator condensate, which was used in the industrial process for these purposes.

Table 1 summarizes the main inputs of the base simulation. The steam flow rates in each step are percentages of the maximum possible flow rate of 8.80 $\mathrm{kg} / \mathrm{s}$, corresponding to the flow rate achieved with total opening of the steam valve.

The modeling of the crystallization processes in the $\mathrm{A}$ and $\mathrm{B}$ vacuum pans encompassed the mass, energy, and population balances. Nucleation and growth rate dispersion were taken into account; the equations representing these phenomena are presented in Section 3. The following assumptions were made, for simplification of the model: (i) the massecuite was perfectly homogeneous throughout the entire pan volume; (ii) its temperature was uniform; (iii) the crystal shape coefficient did not vary during the process; (iv) all the steam supplied was condensed (Chorão, 1995; Georgieva et al., 2003; Jesus, 2004).

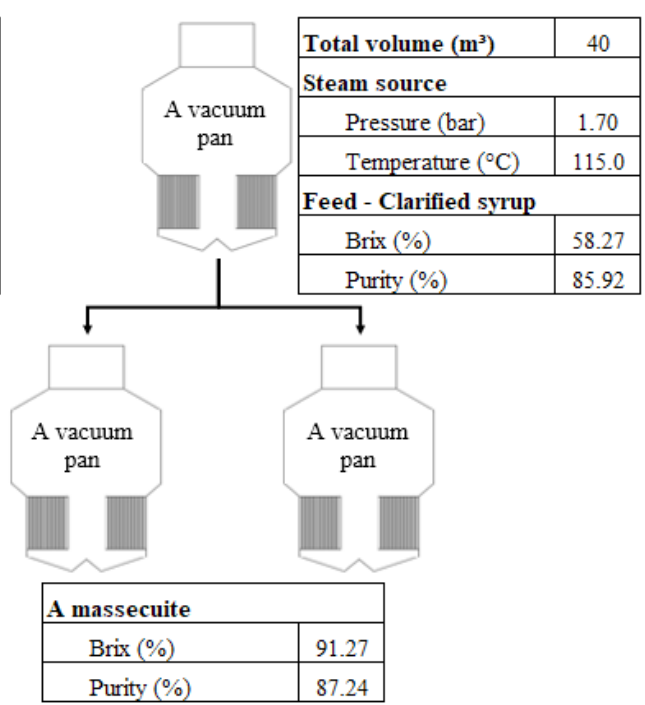

In industries that do not produce ethanol, there is interest in exhausting the massecuite, reducing its purity as much as possible. These industries usually employ the three-massecuite system and the crystallizers are used to continue the crystallization process by cooling the massecuite to about $50{ }^{\circ} \mathrm{C}$ (using natural or forced cooling). In natural cooling crystallizers, long residence times of around two or three days are required, while this time is reduced to about 15 hours in forced cooling crystallizers. After this time, the massecuite needs to be reheated in order to decrease its viscosity and allow centrifugation (Hugot, 1986; Payne, 1989).

In most Brazilian sugar industries, including the one studied here, there is no interest in exhausting the massecuite, since the final molasses is sent to the ethanol production unit (Fernandes, 2011). Hence, the twomassecuite system is preferred and the crystallizers are simply used as buffer tanks between the vacuum pans and the centrifuges. There is no water circulation for forced cooling of the massecuite, and the crystallizers receive the massecuite within short time intervals, so there is no significant cooling to promote additional crystal growth. Therefore, the A and B crystallizers were modeled as massecuite tanks with the sole role of ensuring a continuous supply to the centrifuges.

Centrifuges separate crystals from the mother liquor. In the B centrifuges, the crystal suspension is called magma, second sugar, or B sugar, and molasses is called final molasses or second molasses. The final molasses proceeds to the ethanol production. In the A centrifuges, the crystals form the wet sugar stream, which proceeds to the steps of drying, bagging, and housing. Molasses is called A molasses, or first molasses (Chen and Chou, 1993; Dias et al., 2015; Hugot, 1986).

The first molasses can be divided into light and heavy molasses in the A centrifuges. Heavy molasses is 
Table 1. Main inputs of the base simulation.

\begin{tabular}{|c|c|c|c|}
\hline & & B massecuite & A massecuite \\
\hline Heating steam pressure & bar & 1.70 & 1.70 \\
\hline Heating steam temperature & ${ }^{\circ} \mathrm{C}$ & 115.0 & 115.0 \\
\hline Water temperature & ${ }^{\circ} \mathrm{C}$ & 90.0 & 90.0 \\
\hline Vacuum pan pressure & bar & 0.23 & 0.23 \\
\hline \multicolumn{4}{|l|}{ Calandria filling } \\
\hline Steam flow rate & $\mathrm{t} / \mathrm{h}$ & 0 & 0 \\
\hline Flow rate of A molasses/magma & $\mathrm{m}^{3} / \mathrm{h}$ & 78.0 & 42.0 \\
\hline Water flow rate & $\mathrm{m}^{3} / \mathrm{h}$ & 0 & 0 \\
\hline Maximum volume & $\mathrm{m}^{3}$ & 26.0 & 14.0 \\
\hline \multicolumn{4}{|l|}{ Concentration } \\
\hline \multicolumn{4}{|l|}{ Steam flow rate } \\
\hline - until supersaturation coefficient 1.06 & $\mathrm{t} / \mathrm{h}$ & 17.4 & 1.9 \\
\hline - after supersaturation coefficient 1.06 & $\mathrm{t} / \mathrm{h}$ & 11.4 & 0.6 \\
\hline \multicolumn{4}{|l|}{ Flow rate of A molasses/syrup } \\
\hline - until supersaturation coefficient 1.06 & $\mathrm{~m}^{3} / \mathrm{h}$ & $\begin{array}{l}\text { Required to compensate for } \\
\text { vaporization }\end{array}$ & $\begin{array}{l}\text { Required to compensate for } \\
\text { vaporization }\end{array}$ \\
\hline - after supersaturation coefficient 1.06 & $\mathrm{~m}^{3} / \mathrm{h}$ & 0 & 0 \\
\hline Water flow rate & $\mathrm{m}^{3} / \mathrm{h}$ & 0 & 0 \\
\hline Maximum volume & $\mathrm{m}^{3}$ & 26.0 & 14.0 \\
\hline \multicolumn{4}{|l|}{ Graining } \\
\hline Steam flow rate & $\mathrm{t} / \mathrm{h}$ & 1.9 & - \\
\hline Flow rate of A molasses & $\mathrm{m}^{3} / \mathrm{h}$ & 0 & - \\
\hline Water flow rate & $\mathrm{m}^{3} / \mathrm{h}$ & 0 & - \\
\hline Maximum volume & $\mathrm{m}^{3}$ & 26.0 & - \\
\hline \multicolumn{4}{|l|}{ Total filling } \\
\hline Steam flow rate & $\mathrm{t} / \mathrm{h}$ & 3.8 & 8.9 \\
\hline Flow rate of A molasses/syrup & $\mathrm{m}^{3} / \mathrm{h}$ & 44.0 & 26 \\
\hline Water flow rate & $\mathrm{m}^{3} / \mathrm{h}$ & 0.8 & 0.2 \\
\hline Maximum volume & $\mathrm{m}^{3}$ & 65.0 & 40.0 \\
\hline \multicolumn{4}{|l|}{ Cut 1} \\
\hline Steam flow rate & $\mathrm{t} / \mathrm{h}$ & 3.8 & 12.7 \\
\hline Flow rate of A molasses/syrup & $\mathrm{m}^{3} / \mathrm{h}$ & 44.0 & 28.0 \\
\hline Water flow rate & $\mathrm{m}^{3} / \mathrm{h}$ & 0.2 & 0.2 \\
\hline Maximum volume & $\mathrm{m}^{3}$ & 130.0 & 80.0 \\
\hline \multicolumn{4}{|l|}{ Cut 2} \\
\hline Steam flow rate & $\mathrm{t} / \mathrm{h}$ & 13.9 & - \\
\hline Flow rate of A molasses & $\mathrm{m}^{3} / \mathrm{h}$ & 50.0 & - \\
\hline Water flow rate & $\mathrm{m}^{3} / \mathrm{h}$ & 0.2 & - \\
\hline Maximum volume & $\mathrm{m}^{3}$ & 195.0 & - \\
\hline \multicolumn{4}{|l|}{ Tightening } \\
\hline Steam flow rate & $\mathrm{t} / \mathrm{h}$ & 25.3 & 16.5 \\
\hline Flow rate of A molasses/syrup & $\mathrm{m}^{3} / \mathrm{h}$ & 0 & 0 \\
\hline Water flow rate & $\mathrm{m}^{3} / \mathrm{h}$ & 0 & 0 \\
\hline Maximum volume & $\mathrm{m}^{3}$ & 195.0 & 80.0 \\
\hline
\end{tabular}

obtained at the beginning of the centrifugation and can be sent to the $\mathrm{B}$ vacuum pans, while light molasses is obtained from crystal washing during the intermediate and final steps of the centrifugation, and can be blended with the clarified syrup to feed the A vacuum pans. In the present modeling, separation of the A molasses was not considered and it was entirely sent to the B vacuum pans. This procedure is mainly adopted in the production of sugar with low color. There are several other variations of the two-massecuite system, such as the filling of the calandria of the graining pan with clarified syrup; the filling of the B vacuum pans with blends of clarified syrup and light and heavy molasses, in varying proportions; and B massecuite cutting in two or four pans. These variations are adopted in order to meet specific goals, or to circumvent process problems in different periods of the season (Chen and Chou, 1993; Hugot, 1986; Sousa et al., 1995).

The centrifuges were modeled as solid-liquid separators in continuous operation. In the B centrifuges, the efficiency of separation between the magma and the molasses was considered to be $90 \%$, while in the A centrifuges, the efficiency of separation between the sugar and the molasses was considered to be $95 \%$. Loss of fine crystals was also considered. The solid streams retained crystals with sizes $\geq 0.20 \mathrm{~mm}$ in the B centrifuges and $\geq 0.30 \mathrm{~mm}$ in the A centrifuges. The masses of the smaller crystals were incorporated into the liquid streams. These sizes were selected so that the simulated molasses purities were similar to the industrial values. 
A magma buffer tank was inserted between the $\mathrm{B}$ centrifuge and the A vacuum pans, with addition of water at a flow rate corresponding to $1 \%$ of the magma inflow. The model included a molasses buffer tank between the A centrifuge and the $\mathrm{B}$ vacuum pans, where the crystals present in the A molasses were dissolved in order to avoid the presence of crystals in the feed to the $\mathrm{B}$ vacuum pans.

The base simulation results were compared to the parameter specifications for the studied industry, as well as to the real mean values of the parameters during the studied period (between June 1 and October $31,2015)$. In order to evaluate the impact of the cane quality on the sugar production, the process simulation for the A vacuum pans was repeated, altering the purity of the clarified syrup to the lowest and highest values obtained during the period studied (81.06 and $87.26 \%$, respectively). The clarified syrup purity is directly related to the sugarcane purity, and is little influenced by the processes prior to crystallization. Therefore, this value does not vary significantly during a single day, but may vary from day to day, or from week to week.

In order to evaluate the influence of instability of sugarcane processing, in the simulation, the clarified syrup brix was changed to the lowest and highest values for the period studied (50.56 and $64.60 \%$, respectively). The variation of this parameter is a direct consequence of processing instability, since it reflects the variations of the juice and steam flow rates in the evaporation stage, prior to crystallization.

In another simulation, the steam pressure in the $\mathrm{A}$ and $B$ vacuum pans was modified from the fixed value of 1.70 bar, according to the sinusoidal function shown in Fig. 3. The amplitude and period of the function

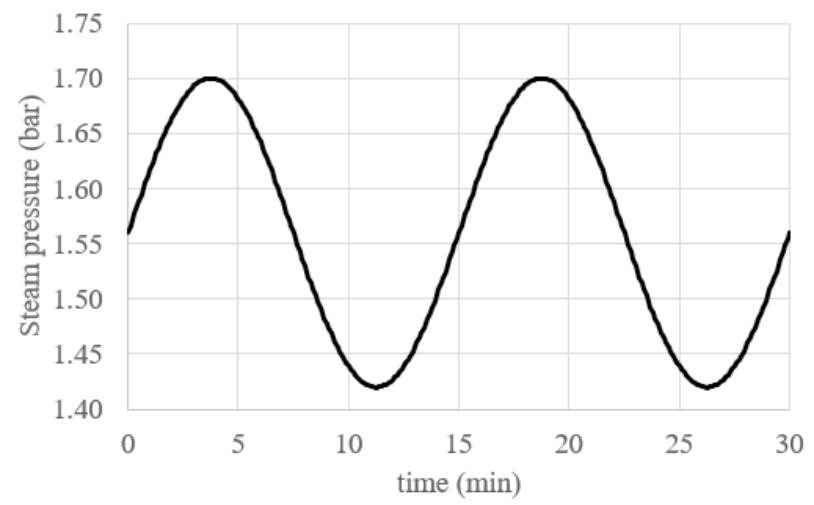

Figure 3. Steam pressure variation according to a sinusoidal function. were selected in order to simulate the variation of this parameter in the industry studied, where the variability results from the instabilities of sugarcane processing and boiler operation. Lastly, the A and B crystallizations were simulated separately, imposing the maximum possible variation of steam flow rate, such that the supersaturation limits of the metastable zone were respected.

Table 2 summarizes the information for the simulations and the changes in the inputs. The results for each simulation were compared to those for the base simulation.

\section{THEORY/CALCULATION}

The mass balances for sucrose, impurities, water, and crystals in the A and B vacuum pans are presented in Eqs. 1-4. The impurities were defined as all the dissolved material other than sucrose (Chorão, 1995; Georgieva et al., 2003; Jesus, 2004). Differences between the equations presented here and those in the cited references are in the terms representing the massecuite outflow, since the step of pan discharging was included in this work.

- Mass balance for sucrose (vacuum pans):

$$
\begin{aligned}
\frac{\mathrm{dM}_{\text {suc }}}{\mathrm{dt}} & =\mathrm{F}_{\mathrm{i}} \cdot \rho_{\mathrm{i}} \cdot\left(1-\frac{\omega_{\mathrm{c}, \mathrm{i}}}{100}\right) \cdot \frac{\mathrm{bx}_{\mathrm{i}}}{100} \cdot \frac{\mathrm{pur}_{\mathrm{i}}}{100}- \\
& -\mathrm{J}_{\mathrm{cris}}-\mathrm{F}_{\mathrm{o}} \cdot \rho_{\mathrm{o}} \cdot\left(1-\frac{\omega_{\mathrm{c}, \mathrm{o}}}{100}\right) \cdot \frac{\mathrm{bx}_{\mathrm{o}}}{100} \cdot \frac{\mathrm{pur}_{\mathrm{o}}}{100}
\end{aligned}
$$

- Mass balance for impurities (vacuum pans):

$$
\begin{aligned}
\frac{\mathrm{dM}_{\mathrm{imp}}}{\mathrm{dt}} & =\mathrm{F}_{\mathrm{i}} \cdot \rho_{\mathrm{i}} \cdot\left(1-\frac{\omega_{\mathrm{c}, \mathrm{i}}}{100}\right) \cdot \frac{\mathrm{bx}_{\mathrm{i}}}{100} \cdot \frac{\left(1-\mathrm{pur}_{\mathrm{i}}\right)}{100}- \\
& -\mathrm{F}_{\mathrm{o}} \cdot \rho_{\mathrm{o}} \cdot\left(1-\frac{\omega_{\mathrm{c}, \mathrm{o}}}{100}\right) \cdot \frac{\mathrm{bx} \mathrm{x}_{\mathrm{o}}}{100} \cdot \frac{\left(1-\mathrm{pur}_{\mathrm{o}}\right)}{100}
\end{aligned}
$$

- Mass balance for water (vacuum pans):

$$
\begin{aligned}
\frac{\mathrm{dM}_{\mathrm{w}}}{\mathrm{dt}} & =\mathrm{F}_{\mathrm{i}} \cdot \rho_{\mathrm{i}} \cdot\left(1-\frac{\omega_{\mathrm{c}, \mathrm{i}}}{100}\right) \cdot \frac{\left(1-\mathrm{bx}_{\mathrm{i}}\right)}{100}- \\
& -\mathrm{J}_{\text {vap }}-\mathrm{F}_{\mathrm{o}} \cdot \rho_{\mathrm{o}} \cdot\left(1-\frac{\omega_{\mathrm{c}, \mathrm{o}}}{100}\right) \cdot \frac{\left(1-\mathrm{bx}_{\mathrm{o}}\right)}{100}
\end{aligned}
$$

Table 2. Summary of the simulations performed.

\begin{tabular}{cccccccc}
\hline Input & \multicolumn{7}{c}{ Simulation } \\
\cline { 2 - 7 } & Base & $\mathbf{1}$ & $\mathbf{2}$ & $\mathbf{3}$ & $\mathbf{4}$ & $\mathbf{5}$ & $\mathbf{6}$ \\
\hline Clarified syrup purity (\%) & 85.92 & 81.06 & 87.26 & 85.92 & 85.92 & 85.92 & 85.92 \\
Clarified syrup brix (\%) & 58.27 & 58.27 & 58.27 & 50.56 & 64.60 & 58.27 & 58.27 \\
Steam pressure (bar) & 1.70 & 1.70 & 1.70 & 1.70 & 1.70 & sinusoidal & 1.70 \\
Maximum steam flow rate (kg/s) & 8.80 & 8.80 & 8.80 & 8.80 & 8.80 & 8.80 & sinusoidal \\
\hline
\end{tabular}


- Mass balance for crystals (vacuum pans):

$\frac{\mathrm{dM}_{\mathrm{c}}}{\mathrm{dt}}=\mathrm{F}_{\mathrm{i}} \cdot \rho_{\mathrm{i}} \cdot \frac{\omega_{\mathrm{c}, \mathrm{i}}}{100}+\mathrm{J}_{\mathrm{cris}}-\mathrm{F}_{\mathrm{o}} \cdot \rho_{\mathrm{o}} \cdot \frac{\omega_{\mathrm{c}, \mathrm{o}}}{100}$

The crystal mass rate, $\mathrm{J}_{\text {cris }}$, results from the population balance. The vaporization rate, $\mathrm{J}_{\text {vap}}$, is given by Eq. 5, where $\mathrm{k}_{\text {vap }}$ reflects the effect of massecuite superheating on the vaporization rate and was considered to be $108 \mathrm{~kg} /\left(\mathrm{h}^{\circ} \mathrm{C}\right)$ (Chorão, 1995; Georgieva et al., 2003; Jesus, 2004).

$$
\mathrm{J}_{\text {vap }}=\frac{\mathrm{Q}_{\mathrm{s} 1}}{\Delta \mathrm{H}_{\text {vap }, \mathrm{s} 2}}+\mathrm{k}_{\text {vap }} \cdot\left(\mathrm{T}-\mathrm{T}_{\text {sat }}-\mathrm{BPE}\right)
$$

In Eq. $5, Q_{s 1}$ is the rate of input of heat supplied by the heating steam, calculated using Eq. 6, where $\alpha$ is a parameter for correction of the heating steam enthalpy, considering heat losses and inaccuracies in the steam pressure meters, and was assumed to have a value of 1.02 (Chorão, 1995; Georgieva et al., 2003).

$\mathrm{Q}_{\mathrm{s} 1}=\mathrm{W}_{\mathrm{s} 1} \cdot \alpha \cdot \Delta \mathrm{H}_{\mathrm{vap}, \mathrm{s} 1}$

The energy balance during the crystallization process is described by Eq. 7 (Chorão, 1995; Georgieva et al., 2003; Jesus, 2004).

- Energy balance (vacuum pans):

$$
\begin{aligned}
& \left(M_{s o l} \cdot C p_{s o l}+M_{c} \cdot C p_{c}\right) \frac{d T}{d t}=Q_{s 1}+F_{i} \cdot \rho_{i} \cdot\left[\left(1-\frac{\omega_{c, i}}{100}\right) \cdot H_{s o l, i}+\frac{\omega_{c, i}}{100} \cdot H_{c, i}\right]- \\
& \text { - } \mathrm{J}_{\text {vap }} \cdot \mathrm{H}_{\mathrm{s} 2}-\mathrm{F}_{\mathrm{o}} \cdot \rho_{\mathrm{o}} \cdot\left[\left(1-\frac{\omega_{\mathrm{c}, \mathrm{o}}}{100}\right) \cdot \mathrm{H}_{\mathrm{sol}, \mathrm{o}}+\frac{\omega_{\mathrm{c}, \mathrm{o}}}{100} \cdot \mathrm{H}_{\mathrm{c}, \mathrm{o}}\right]- \\
& \text { - } H_{\text {sol }} \cdot\left(\frac{\mathrm{dM}_{\text {suc }}}{d t}+\frac{\mathrm{dM}_{\mathrm{imp}}}{\mathrm{dt}}+\frac{\mathrm{dM}_{\mathrm{w}}}{\mathrm{dt}}\right)-\mathrm{H}_{\mathrm{c}} \cdot \frac{\mathrm{dM}_{\mathrm{c}}}{\mathrm{dt}}- \\
& -\frac{d H_{\text {sol }}}{d \frac{b x_{\text {sol }}}{100}} \cdot\left[\left(1-\frac{b x_{\text {sol }}}{100}\right) \cdot\left(\frac{\mathrm{dM}_{\text {suc }}}{d t}+\frac{d M_{\text {imp }}}{d t}\right)-\frac{b x_{\text {sol }}}{100} \cdot \frac{d M_{w}}{d t}\right]- \\
& -\left(\frac{1}{\frac{\mathrm{bx}_{\mathrm{sol}}}{100}}\right) \cdot \frac{\mathrm{dH}_{\mathrm{sol}}}{\mathrm{d} \frac{\mathrm{pur}_{\mathrm{sol}}}{100}} \cdot\left[\left(1-\frac{\mathrm{pur}_{\mathrm{sol}}}{100}\right) \cdot \frac{\mathrm{dM}_{\mathrm{suc}}}{\mathrm{dt}}-\frac{\mathrm{pur}_{\mathrm{sol}}}{100} \cdot \frac{\mathrm{dM}_{\mathrm{imp}}}{\mathrm{dt}}\right]
\end{aligned}
$$

The crystal population density, $\mathrm{n}$, is defined as the relation between the number of crystals, $\mathrm{N}$, and their size, L, in a given volume of solution, for an infinitesimal range of L (Eq. 8). Hence, the population balance, disregarding the phenomena of crystal agglomeration and breakage, can be described by Eq. 9, where $\mathrm{G}$ is the linear crystal growth rate and $\mathrm{D}_{\mathrm{g}}$ is the growth rate dispersion. In this equation, the crystal growth rate is assumed to be independent of crystal size, a hypothesis known as McCabe's Law (Mersmann, 2001; Mullin, 2001).

$$
\mathrm{n}(\mathrm{L})=\lim _{\mathrm{L} \rightarrow 0} \frac{\Delta \mathrm{N}}{\Delta \mathrm{L}}=\frac{\mathrm{dN}}{\mathrm{dL}}
$$

$$
\frac{\partial \mathrm{n}}{\partial \mathrm{t}}+\mathrm{G} \cdot \frac{\partial \mathrm{n}}{\partial \mathrm{L}}-\mathrm{D}_{\mathrm{g}} \frac{\partial^{2} \mathrm{n}}{\partial \mathrm{L}^{2}}=0
$$

Since the partial differential equation described above has no simple analytical solution, the population balance is conveniently replaced for modeling purposes by the set of ordinary differential equations representing the distribution moments, $\mu_{\mathrm{i}}$ :

$\frac{\mathrm{d} \mu_{0}}{\mathrm{dt}}=\mathrm{B}^{0}$

$\frac{\mathrm{d} \mu_{1}}{\mathrm{dt}}=\mathrm{G} \cdot \mu_{0}+\mathrm{D}_{\mathrm{g}} \cdot \frac{\mathrm{B}^{0}}{\mathrm{G}}$

$\frac{\mathrm{d} \mu_{\mathrm{j}}}{\mathrm{dt}}=\mathrm{j} \cdot \mathrm{G} \cdot \mu_{\mathrm{j}-1}+\mathrm{j} \cdot(\mathrm{j}-1) \cdot \mathrm{D}_{\mathrm{g}} \cdot \mu_{\mathrm{j}-2}, \mathrm{j}=2$ to 5

The crystal mass rate, $J_{\text {cris }}$ is related to the third distribution moment according to Eq. 13, where $\mathrm{k}_{\mathrm{v}}$ is the crystal shape factor, considered to be 0.75 (Jesus, 2004).

$J_{\text {cris }}=\rho_{\mathrm{c}} \cdot \mathrm{k}_{\mathrm{v}} \cdot \frac{\mathrm{d} \mu_{3}}{\mathrm{dt}}$

In order to calculate the linear crystal growth rate, $\mathrm{G}$, the growth rate dispersion, $\mathrm{D}_{\mathrm{g}}$, and the nucleation rate, $\mathrm{B}_{0}$, Eqs. 14-16 were used, respectively, assuming values of 887 for $\mathrm{K}_{\mathrm{g}}$ and $5.10^{-5}$ for $\mathrm{Kd}_{\mathrm{g}}$ (Chorão, 1995; Jesus, 2004). The empirical fit described by Eq. 17 was used to calculate the nucleation parameter, $\mathrm{K}_{\mathrm{n}}$.

$$
\begin{aligned}
\mathrm{G} & =\mathrm{K}_{\mathrm{g}} \cdot \exp \left(\frac{-57000}{\mathrm{R} \cdot(\mathrm{T}+273.15)}\right) \cdot(\mathrm{S}-1) \cdot \\
\cdot & \exp \left[-8 \cdot\left(1-\frac{\mathrm{pur}_{\mathrm{sol}}}{100}\right)\right] \cdot\left(1+\frac{2 \cdot \mathrm{V}_{\mathrm{c}}}{\mathrm{V}_{\text {susp }}}\right)
\end{aligned}
$$

$D_{g}=K_{g} \cdot\left(2 \cdot \frac{p_{\text {sol }}}{100}-1\right) \cdot G$

$\mathrm{B}^{0}=\mathrm{V}_{\text {susp }} \cdot \mathrm{K}_{\mathrm{n}} \cdot 2.894 \cdot 10^{12} \cdot \mathrm{G}^{0.51} \cdot\left(\frac{\mu_{3}}{\mathrm{~V}_{\text {susp }}}\right)^{0.53}$

$\mathrm{K}_{\mathrm{n}}=1.15 \cdot 10^{-4} \cdot \exp \left[22.10 \cdot\left(1-\frac{\mathrm{pur}_{\text {sol }}}{100}\right)\right]$

The mass balances in the centrifuges were described by Eqs. 18-25, where $\beta$ is the percentage efficiency of solid-liquid separation and $\eta$ is the crystal mass 
percentage of the produced solid stream. The energy balance is shown in Eq. 26, where the condition described by Eq. 27 was imposed.

- Mass balance for sucrose (centrifuges):

$$
\begin{aligned}
\mathrm{F}_{\mathrm{m}} \cdot \rho_{\mathrm{m}} \cdot\left(1-\frac{\omega_{\mathrm{c}, \mathrm{m}}}{100}\right) \cdot \frac{\mathrm{bx}}{100} \cdot \frac{\mathrm{pur}}{100} \cdot \frac{\beta}{100}= & \mathrm{F}_{\mathrm{mol}} \cdot \rho_{\mathrm{mol}} \cdot \\
\cdot & \left(1-\frac{\omega_{\mathrm{c}, \mathrm{mol}}}{100}\right) \cdot \frac{\mathrm{bx}_{\mathrm{mol}}}{100} \cdot \frac{\mathrm{pur}_{\mathrm{mol}}}{100}
\end{aligned}
$$

$\mathrm{F}_{\mathrm{m}} \cdot \rho_{\mathrm{m}} \cdot\left(1-\frac{\omega_{\mathrm{c}, \mathrm{m}}}{100}\right) \cdot \frac{\mathrm{bx} \mathrm{m}_{\mathrm{m}}}{100} \cdot \frac{\mathrm{pur}}{100} \cdot\left(1-\frac{\beta}{100}\right)=\mathrm{F}_{\mathrm{sug}} \cdot \rho_{\mathrm{sug}}$

$$
\left(1-\frac{\omega_{\mathrm{c}, \text { sug }}}{100}\right) \cdot \frac{\mathrm{bx}_{\mathrm{sug}}}{100} \cdot \frac{\mathrm{pur}_{\mathrm{sug}}}{100}
$$

- Mass balance for impurities (centrifuges):

$$
\begin{aligned}
& \mathrm{F}_{\mathrm{m}} \cdot \rho_{\mathrm{m}} \cdot\left(1-\frac{\omega_{\mathrm{c}, \mathrm{m}}}{100}\right) \cdot \frac{\mathrm{bx}_{\mathrm{m}}}{100} \cdot\left(1-\frac{\mathrm{pur}_{\mathrm{m}}}{100}\right) \cdot \frac{\beta}{100}= \mathrm{F}_{\mathrm{mol}} \cdot \rho_{\mathrm{mol}} \cdot \\
& \cdot\left(1-\frac{\omega_{\mathrm{c}, \mathrm{mol}}}{100}\right) \cdot \frac{\mathrm{bx}_{\mathrm{mol}}}{100} \cdot\left(1-\frac{\mathrm{pur}_{\mathrm{mol}}}{100}\right)
\end{aligned}
$$

$$
\begin{aligned}
& \mathrm{F}_{\mathrm{m}} \cdot \rho_{\mathrm{m}} \cdot\left(1-\frac{\omega_{\mathrm{c}, \mathrm{m}}}{100}\right) \cdot \frac{\mathrm{bx}_{\mathrm{m}}}{100} \cdot\left(1-\frac{\mathrm{pur}_{\mathrm{m}}}{100}\right) \cdot\left(1-\frac{\beta}{100}\right)= \mathrm{F}_{\text {sug }} \cdot \rho_{\text {sug }} \cdot \\
& \cdot\left(1-\frac{\omega_{\mathrm{c}, \mathrm{sug}}}{100}\right) \cdot \frac{\mathrm{bx}_{\text {sug }}}{100} \cdot\left(1-\frac{\mathrm{pur}_{\text {sug }}}{100}\right)
\end{aligned}
$$

- Mass balance for water (centrifuges):

$$
\begin{aligned}
& \mathrm{F}_{\mathrm{m}} \cdot \rho_{\mathrm{m}} \cdot\left(1-\frac{\omega_{\mathrm{c}, \mathrm{m}}}{100}\right) \cdot\left(1-\frac{b x_{\mathrm{m}}}{100}\right) \cdot \frac{\beta}{100}+\mathrm{F}_{\mathrm{w}} \cdot \rho_{\mathrm{w}}=\mathrm{F}_{\mathrm{mol}} \cdot \rho_{\mathrm{mol}} \cdot \\
& \cdot\left(1-\frac{\omega_{\mathrm{c}, \mathrm{mol}}}{100}\right) \cdot\left(1-\frac{b x_{\mathrm{mol}}}{100}\right)
\end{aligned}
$$

$\mathrm{F}_{\mathrm{m}} \cdot \rho_{\mathrm{m}} \cdot\left(1-\frac{\omega_{\mathrm{c}, \mathrm{m}}}{100}\right) \cdot\left(1-\frac{\mathrm{bx} \mathrm{m}}{100}\right) \cdot\left(1-\frac{\beta}{100}\right)=\mathrm{F}_{\mathrm{sug}} \cdot \rho_{\mathrm{sug}} \cdot$

$$
\left(1-\frac{\omega_{\mathrm{c}, \text { sug }}}{100}\right) \cdot\left(1-\frac{\mathrm{bx}_{\mathrm{sug}}}{100}\right)
$$

- Mass balance for crystals (centrifuges):

$$
\begin{aligned}
& \mathrm{F}_{\mathrm{m}} \cdot \rho_{\mathrm{m}} \cdot \frac{\omega_{\mathrm{c}, \mathrm{m}}}{100} \cdot\left(1-\frac{\eta}{100}\right)=\mathrm{F}_{\mathrm{mol}} \cdot \rho_{\mathrm{mol}} \cdot \frac{\omega_{\mathrm{c}, \mathrm{mol}}}{100} \\
& \mathrm{~F}_{\mathrm{m}} \cdot \rho_{\mathrm{m}} \cdot \frac{\omega_{\mathrm{c}, \mathrm{m}}}{100} \cdot \frac{\eta}{100}=\mathrm{F}_{\mathrm{sug}} \cdot \rho_{\mathrm{sug}} \cdot \frac{\omega_{\mathrm{c}, \mathrm{sug}}}{100}
\end{aligned}
$$

- Energy balance (centrifuges):

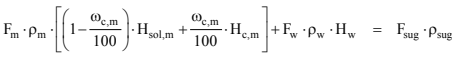

$$
\begin{aligned}
& {\left[\left(1-\frac{\omega_{c, s, y g}}{100}\right) \cdot H_{\text {sol, sug }}+\frac{\omega_{c, s, y g}}{100} \cdot H_{c, s, y g}\right]+} \\
& +F_{\text {mal }} \cdot \rho_{\text {mol }} \cdot\left[\left(1-\frac{\omega_{c, \text { mol }}}{100}\right) \cdot H_{\text {sol, nal }}+\frac{\omega_{c, \text { cmol }}}{100} \cdot H_{c, \text { mol }}\right]
\end{aligned}
$$

$\mathrm{T}_{\text {sug }}=\mathrm{T}_{\mathrm{mol}}$
The other equations of the model, such as the correlations for physical properties, are presented in Appendix A.

\section{RESULTS AND DISCUSSION}

Fig. 4 shows the following parameters for processing of the B massecuite, as a function of time, resulting from the base simulation: (a) volume of solution/suspension, (b) temperature, (c) crystal mass, (d) mass percentage of crystals, (e) supersaturation and critical supersaturation, (f) brix and purity, and (g) crystal mean size. The vertical dashed lines in Figs. $4(\mathrm{a})-4(\mathrm{~g})$ indicate the divisions between the process steps: filling the calandria of the graining vacuum pan (20 $\mathrm{min})$, concentration (5 $\mathrm{min})$, graining (5 $\mathrm{min})$, total filling (58 $\mathrm{min})$, cut 1 (90 $\mathrm{min})$, cut 2 (105 $\mathrm{min})$, tightening (28 $\mathrm{min})$, and discharging $(20 \mathrm{~min})$. The overall duration of the $\mathrm{B}$ massecuite process (from calandria filling until tightening) was $311 \mathrm{~min}$ (5.19 h). Fig. 4(h) shows the crystal size distribution for the $\mathrm{B}$ massecuite at the end of the process. The vertical dashed line in Fig. 4(h) indicates the separation of fine crystals in the B centrifuges. Elimination of crystals smaller than $0.20 \mathrm{~mm}$ resulted in a loss of $17.7 \%$ of the crystal mass in the B massecuite to the final molasses, while increasing the crystal mean size from $0.347 \mathrm{~mm}$ to $0.411 \mathrm{~mm}$.

During the filling of the calandria with the A molasses, no steam was supplied to the pan. Hence, the volume of the solution inside the vacuum pan increased and the temperature, brix, and purity remained constant. In the concentration step, the molasses feed was interrupted and the steam supply was started. Consequently, water evaporation also started. The solution volume then decreased slightly, the temperature increased, the supersaturation coefficient increased to near the critical limit, and the brix increased. The solution purity remained constant during the concentration step, since the removal of water caused the brix and the pol to increase in the same proportions.

The seed growth started during the graining step. In the steps of filling, cut 1 and cut 2, the flow rate of the evaporated water was lower than the inflow of the A molasses, causing the volume occupied by the suspension to gradually increase to the maximum limit of $195 \mathrm{~m}^{3}$. During these steps, there were increases of the mass of crystals as well as the crystal mean size. The supersaturation coefficient was maintained within the limits of the metastable zone, between 1.0 and the critical limit. The brix remained close to $78 \%$, due to compensation of the molasses feed and sucrose crystallization by water evaporation. The purity decreased gradually, due to the progressive decrease of sucrose in solution as it was gradually incorporated 
a.
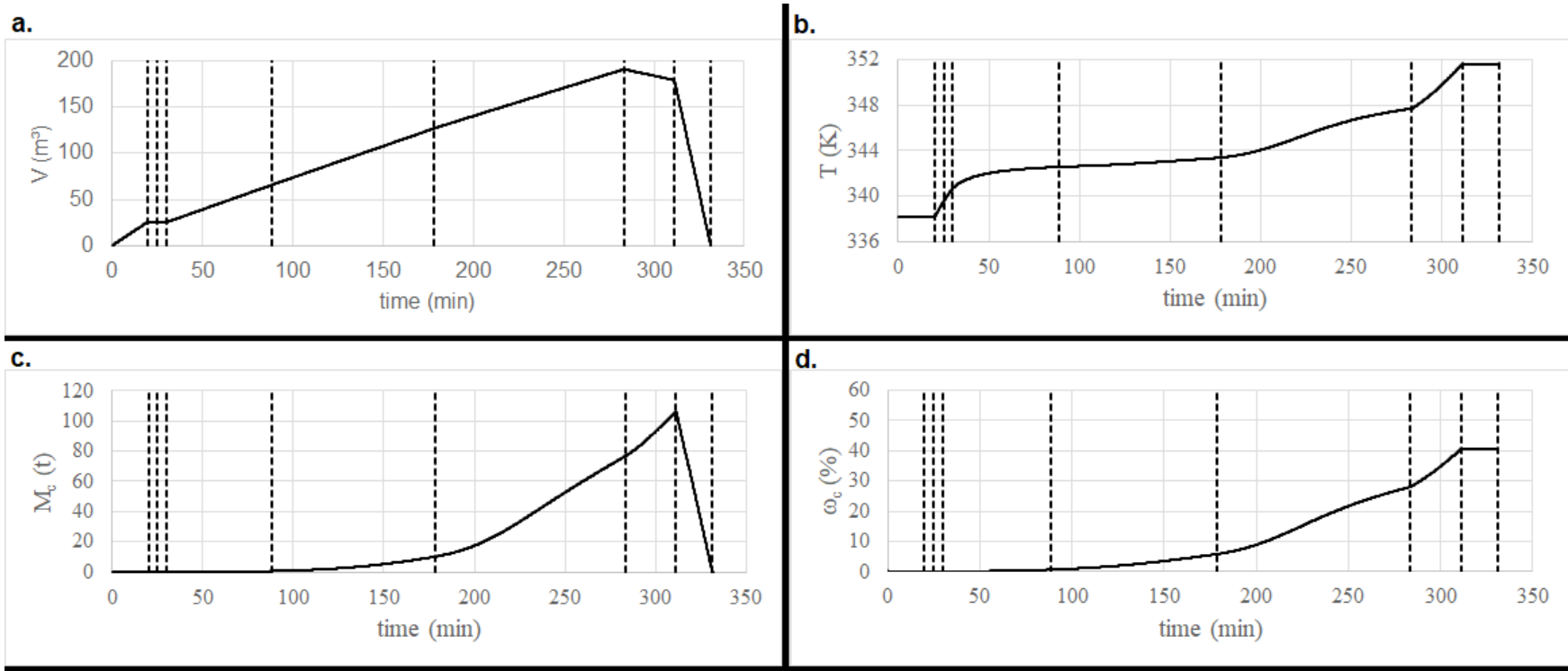

e.
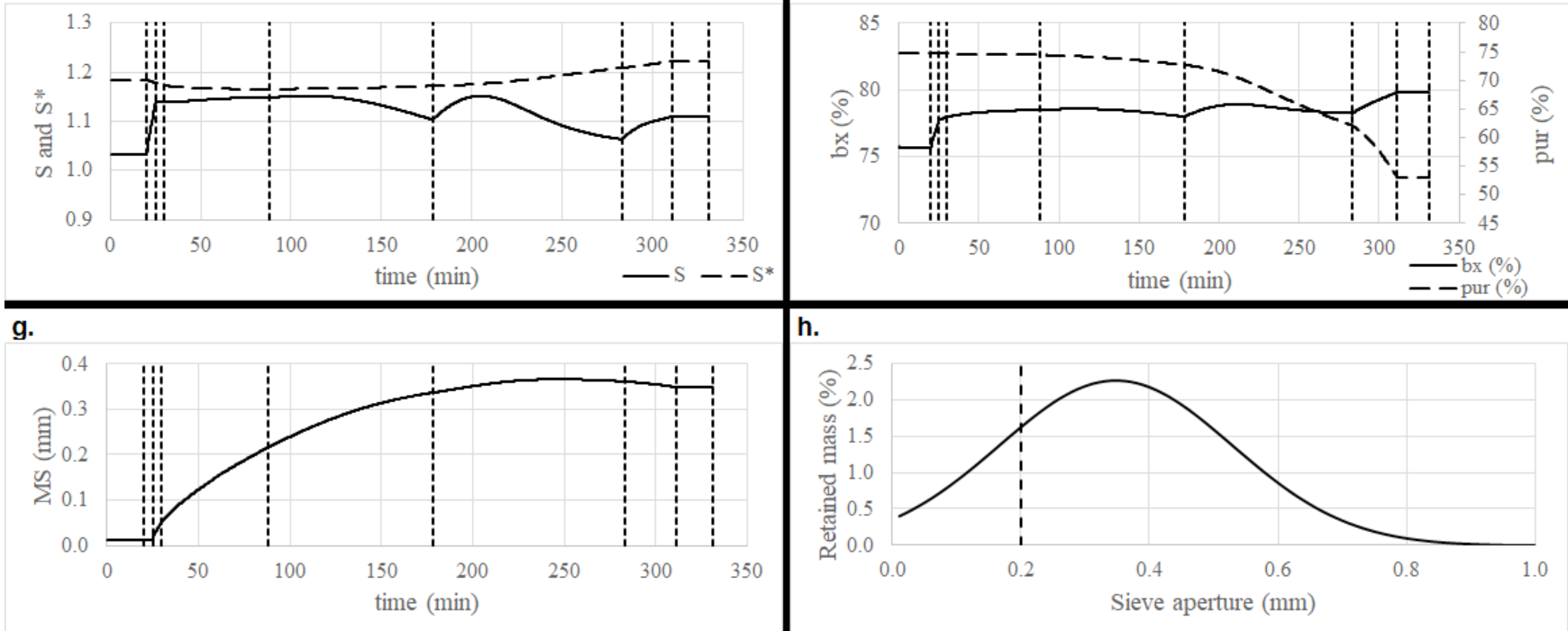

Figure 4. Base simulation results for the B massecuite: (a) volume of solution/suspension, (b) temperature, (c) crystal mass, (d) mass percentage of crystals, (e) supersaturation and critical supersaturation, (f) brix and purity, (g) crystal mean size, and (h) crystal size distribution at the end of the process. The vertical dashed lines in (a)(g) indicate the divisions between the process steps. The vertical dashed line in $(\mathrm{h})$ indicates separation of the fine crystals in the B centrifuges.

into the crystals. The decrease in purity caused the temperature to rise, following the increase in the boiling point elevation of the solution. During cut 2, the crystal mean size stabilized due to the decrease in the crystal growth rate caused by the drop in solution purity.

During the tightening step, the A molasses feed was interrupted again, causing a new contraction in the massecuite volume and an increase in the brix. Sucrose crystallization continued to occur, as evidenced by the increase of the crystal mass and the decrease of the solution purity. During the discharging, crystallization was discontinued. The suspension volume and the crystal mass were the only variables that changed during this stage.
The same variables for A massecuite processing are presented in Fig. 5. The A massecuite processing steps were: calandria filling (20 min), concentration (10 $\mathrm{min})$, total filling $(90 \mathrm{~min})$, cut 1 (138 $\mathrm{min})$, tightening (15 $\mathrm{min})$, and discharging $(20 \mathrm{~min})$. The duration of the A massecuite process (from calandria filling until tightening) was $273 \mathrm{~min}(4.56 \mathrm{~h})$. The crystal size distribution of the A massecuite at the end of the process is shown in Fig. 5(h). The elimination of crystals smaller than $0.30 \mathrm{~mm}$ in the A centrifuges resulted in a loss of $9.2 \%$ of the crystal mass in the A massecuite to the A molasses, and increased the crystal mean size from 0.595 to $0.639 \mathrm{~mm}$.

Unlike in the B massecuite processing, the solution purity increased during the filling with clarified syrup, 
a.
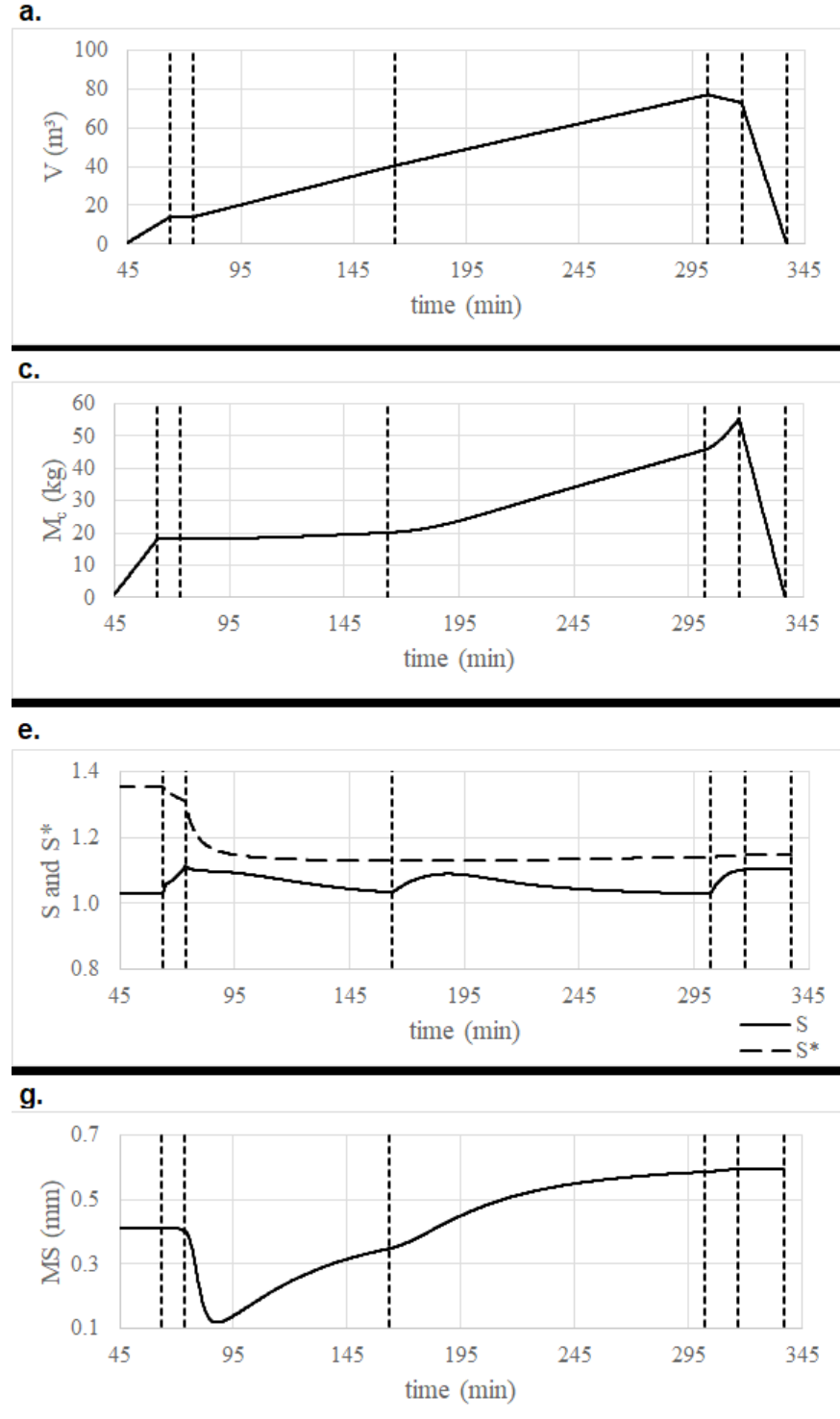

b.

d.

f.

h.
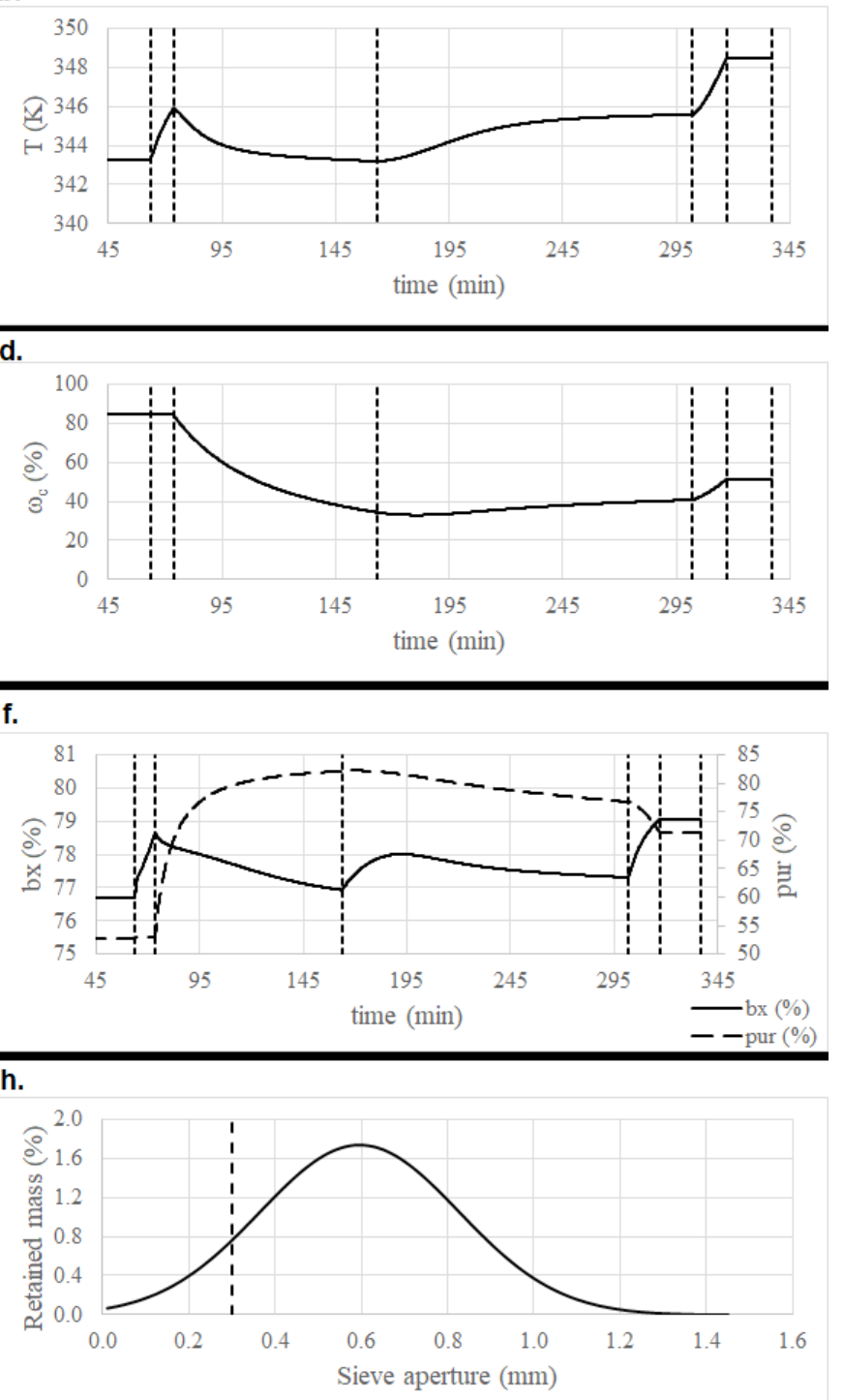

Figure 5. Base simulation results for the A massecuite: (a) volume of solution/suspension, (b) temperature, (c) crystal mass, (d) mass percentage of crystals, (e) supersaturation and critical supersaturation, (f) brix and purity, (g) crystal mean size, and (h) crystal size distribution at the end of the process. The vertical dashed lines in (a)(g) indicate the divisions between the process steps. The vertical dashed line in $(\mathrm{h})$ indicates the separation of fine crystals in the A centrifuges.

since the purity of this material was higher than the purity of the magma used to fill the calandria of the A vacuum pan. The brix decreased during this step, what caused the temperature to decrease, following the decrease of the boiling point elevation of the solution. The mass percentage of crystals in the massecuite also decreased, since there were no crystals in the clarified syrup that fed the pan. The crystal mean size decreased due to the occurrence of secondary nucleation phenomena at the end of the concentration step. The brix reached a maximum at the end of the concentration step, which increased the supersaturation to a degree that allowed secondary nucleation to occur. From cut 1 to the end of the process, the variables followed the same trends observed in the B massecuite processing. The increase of the metastable zone at the end of the process was not so pronounced as it was in the B massecuite processing. This occurred because the purity drop in A massecuite was less intense than in $B$ massecuite. The critical supersaturation, that is the upper limit of the metastable zone, is a function of the square of the purity (Eq. A.15).

Table 3 compares the base simulation results, the specifications for each variable in the studied industry, and the real mean values for the period between June 1 and October 31, 2015. The simulation results satisfactorily approximated the expected values. In the simulation, the variables related to the sugar produced (pol, MS, and CV) refer to the wet sugar stream immediately after centrifugation, while the 
Table 3. Comparison of the base simulation results, the specifications of the variables in the studied industry, and the real mean values of the variables for the period between June 1 and October 31, 2015.

\begin{tabular}{cccc}
\hline & Base simulation & Specification & Real mean value \\
\hline Time of B massecuite process (h) & 5.19 & $4.5-6.0$ & - \\
Crystal mass percentage in B massecuite (\%) & 40.54 & $40-45$ & 41.92 \\
Magma purity (\%) & 94.15 & - & 93.13 \\
Final molasses purity (\%) & 59.58 & $<65$ & 59.79 \\
Time of A massecuite process (h) & 4.56 & $4.0-5.0$ & - \\
Crystal mass percentage in A massecuite (\%) & 51.13 & $50-55$ & 45.19 \\
Sugar pol (\%) & 97.82 & the higher the better & 99.80 \\
MS after centrifugation (mm) & 0.64 & $0.60-0.70$ & 0.65 \\
CV after centrifugation (\%) & 30.58 & the lower the better & 25.36 \\
A molasses brix (\%) & 75.67 & - & 75.71 \\
A molasses purity (\%) & 74.65 & $75-80$ & 74.59 \\
\hline
\end{tabular}

specifications for these variables, as well as their real mean values, refer to the sugar after passing through the dryers, a step that was not considered in the simulation. Since fine crystals were separated in the dryers, the real MS was higher than the simulated $\mathrm{MS}$, and the real CV was lower than the simulated CV. Sugar pol increases during drying, because residual water in the sugar is eliminated. The sugar moisture content, which is approximately $1-2 \%$ at the exit of the centrifuges, is reduced to values of around $0.03 \%$ in the dryers (Chen and Chou, 1993; Hugot, 1986).

In Table 4, the results of the base simulation for the A massecuite process are compared to the results of simulations 1 and 2, in which the clarified syrup purity was altered to the lowest and highest values in the studied period, respectively.

The mass percentage of crystals in the A massecuite was not influenced by the alterations in the clarified syrup purity. However, the crystal size distribution changed. In simulation 1 (lower syrup purity), the crystal mean size decreased to $0.53 \mathrm{~mm}$ after centrifugation, characterizing out-of-specification sugar production. In simulation 2 (higher syrup purity), the crystal mean size increased, but remained within the desired range (0.60-0.70 mm).
Due to the change in the crystal size distribution, the separation of crystals smaller than $0.30 \mathrm{~mm}$ in the centrifugation, which in the base simulation, caused a loss of $9.2 \%$ of the crystal mass originally contained in the massecuite, resulted in losses of $20.2 \%$ in simulation 1 and $7.1 \%$ in simulation 2 . Therefore, simulation 1 showed a sugar outflow in the A centrifuges that was $14.0 \%$ lower than the sugar outflow in the base simulation. On the other hand, sugar production increased by $2.8 \%$ in simulation 2 , compared to the base simulation. No changes in the syrup and steam consumptions were observed in simulations 1 and 2, compared to the base simulation. In simulation 1, the molasses purity decreased and its brix increased, indicating that the impurities present in the clarified syrup were mainly transferred to the molasses stream. The opposite occurred in simulation 2.

In order to try to achieve the desired sugar specification, simulation 1 was repeated, but with modification of the times and flow rates of syrup and steam in each step. However, although the crystal mass percentage in the massecuite reached the desired range, the crystal size distribution did not change. Table 5 presents the results of this simulation (simulation

Table 4. Comparison of the results for the base simulation and for simulations 1 and 2 , in which the clarified syrup purity was changed.

\begin{tabular}{|c|c|c|c|}
\hline & Base simulation & Simulation 1 & Simulation 2 \\
\hline Clarified syrup purity (\%) & 85.92 & 81.06 & 87.26 \\
\hline Time of A massecuite process $(\mathrm{h})$ & 4.56 & 4.56 & 4.56 \\
\hline Crystal mass percentage in A massecuite (\%) & 51.13 & 49.44 & 51.57 \\
\hline MS before centrifugation (mm) & 0.59 & 0.46 & 0.64 \\
\hline CV before centrifugation ( $\%)$ & 38.81 & 44.06 & 37.13 \\
\hline Massecuite inflow in A centrifuges $\left(\mathrm{m}^{3} / \mathrm{h}\right)$ & 13.00 & 13.00 & 13.00 \\
\hline Sugar outflow in A centrifuges $\left(\mathrm{m}^{3} / \mathrm{h}\right)$ & 6.02 & 5.18 & 6.19 \\
\hline MS after centrifugation (mm) & 0.64 & 0.53 & 0.67 \\
\hline $\mathrm{CV}$ after centrifugation $(\%)$ & 30.58 & 28.66 & 30.53 \\
\hline Molasses outflow in A centrifuges $\left(\mathrm{m}^{3} / \mathrm{h}\right)$ & 7.68 & 8.52 & 7.50 \\
\hline A molasses brix $(\%)$ & 75.67 & 78.21 & 75.06 \\
\hline A molasses purity $(\%)$ & 74.65 & 71.50 & 75.98 \\
\hline Syrup consumption in A massecuite process $\left(\mathrm{m}^{3}\right)$ & 104 & 104 & 104 \\
\hline Steam consumption in A massecuite process $(\mathrm{t})$ & 47 & 47 & 47 \\
\hline
\end{tabular}


Table 5. Comparison of the results for the base simulation and for simulations 1 and 1', in which the clarified syrup purity was reduced.

\begin{tabular}{|c|c|c|c|}
\hline & Base simulation & Simulation 1 & Simulation 1' \\
\hline Clarified syrup purity (\%) & 85.92 & 81.06 & 81.06 \\
\hline Time of A massecuite process (h) & 4.56 & 4.56 & 4.64 \\
\hline Crystal mass percentage in A massecuite (\%) & 51.13 & 49.44 & 51.74 \\
\hline MS before centrifugation (mm) & 0.59 & 0.46 & 0.45 \\
\hline CV before centrifugation $(\%)$ & 38.81 & 44.06 & 44.83 \\
\hline Massecuite inflow in A centrifuges $\left(\mathrm{m}^{3} / \mathrm{h}\right)$ & 13.00 & 13.00 & 13.00 \\
\hline Sugar outflow in A centrifuges $\left(\mathrm{m}^{3} / \mathrm{h}\right)$ & 6.02 & 5.18 & 5.38 \\
\hline Sugar pol $(\%)$ & 97.82 & 97.54 & 97.19 \\
\hline MS after centrifugation $(\mathrm{mm})$ & 0.64 & 0.53 & 0.53 \\
\hline $\mathrm{CV}$ after centrifugation $(\%)$ & 30.58 & 28.66 & 28.87 \\
\hline Molasses outflow in A centrifuges $\left(\mathrm{m}^{3} / \mathrm{h}\right)$ & 7.68 & 8.52 & 8.32 \\
\hline A molasses brix $(\%)$ & 75.67 & 78.21 & 78.37 \\
\hline A molasses purity $(\%)$ & 74.65 & 71.50 & 70.69 \\
\hline Syrup consumption in A massecuite process $\left(\mathrm{m}^{3}\right)$ & 104 & 104 & 104 \\
\hline Steam consumption in A massecuite process $(\mathrm{t})$ & 47 & 47 & 47 \\
\hline
\end{tabular}

1'), in which sugar production remained low, because there was still a substantial loss of fine crystals in the centrifugation. Sugar production in simulation 1' was slightly higher than in simulation 1 , due to the increase in crystal mass percentage in the massecuite.

In general, any impurity tends to reduce the sucrose crystallization rate, although the latter depends not only on the impurity concentration, but also on its composition. Even at low concentrations, impurities can significantly affect crystal growth rate, shape, and size distribution, because they alter the solution properties and selectively adsorb on different faces of the crystal (Chen and Chou, 1993; Chorão, 1995; Mullin, 2001).

Inorganic compounds, such as potassium, sodium, calcium, and iron in the form of chlorides, sulfates, carbonates, silicates, and sulfites are commonly present in sugar crystals. These saline substances originate from the sugarcane juice itself and are incorporated during the industrial process, especially the juice treatment (Merheb, 2014; Schlumbach et al., 2017). The analysis used to quantify the presence of these impurities in the produced sugar is based on electrical conductivity, and the result is known as ash concentration (ICUMSA, 2015). The values in the studied industry were around $0.05 \%$.

Another group of impurities is composed of particles of color contrasting with that of the sugar crystals, such as rust, iron dusts, bagasse, caramel compounds, and soot. The presence of this type of impurity, called black point, is quantified by visual counting (Lopes and Borges, 2004; Oliveira et al., 2007). In the studied industry, the black point concentration was around 15 per $100 \mathrm{~g}$ of sugar.

Monosaccharides such as glucose and fructose, and polysaccharides such as starch and dextran are also commonly present in sugar crystals. Glucose and fructose are present in cane juice and are also produced during the industrial process as a result from sucrose hydrolysis (Fernandes, 2011). The concentration of these monosaccharides in the produced sugar of the studied industry was approximately $0.03 \%$. Starch is produced by the sugarcane itself, and is found mainly in the leaves, internodes, and tops. It is partially removed during juice treatment and sugar manufacture, but part of it remains in the process and ends up in the sugar crystals. On the other hand, dextran results from the action on sucrose of microorganisms of the genus Leuconostoc (ICUMSA, 2015; Lopes and Borges, 2004; Oliveira et al., 2007). The concentrations of both polysaccharides in the studied process were about $140 \mathrm{mg}$ per $\mathrm{kg}$ of sugar.

Zaorska (1968) and Zagrodzki and Zaorska (1974) determined the relation between sucrose solution purity and the decrease of crystal growth rate from experiments with impure industrial solutions. This relation, which was used by Chorão (1995), Georgieva et al. (2003), and Jesus (2004), was also considered in this work in the multiplication of the exponential term referring to solution purity, in the linear crystal growth rate equation (Eq. 14).

In the crystallization experiments using vacuum evaporation performed by Merheb (2014), increased dextran contamination led to decreases of the crystal growth rate and the crystal mean size, although it did not affect the crystal mass per solution volume.

The average crystal mass rate in the base simulation was $8.76 \times 10^{3} \mathrm{~kg} / \mathrm{h}$, which decreased to $8.37 \times 10^{3} \mathrm{~kg} / \mathrm{h}$ in the simulation with low syrup purity, and increased to $8.88 \times 10^{3} \mathrm{~kg} / \mathrm{h}$ in the simulation with high syrup purity. The linear crystal growth rate, which presented an average of $3.90 \times 10^{-8} \mathrm{~m} / \mathrm{s}$ in the base simulation, decreased to $3.32 \times 10^{-8} \mathrm{~m} / \mathrm{s}$ in the simulation with low purity, and increased to $4.08 \cdot 10^{-8} \mathrm{~m} / \mathrm{s}$ in the simulation with high purity.

Table 6 presents the results of the simulations in which the syrup brix was altered. In simulations 3 and 4 , the times of each step were not modified and the 
Table 6. Comparison of the results for the base simulation and for simulations 3, 3', 4, and 4', in which the clarified syrup brix was changed.

\begin{tabular}{|c|c|c|c|c|c|}
\hline & Base simulation & Simulation 3 & Simulation 3' & Simulation 4 & Simulation 4' \\
\hline Clarified syrup brix (\%) & 58.27 & 50.56 & 50.56 & 64.60 & 64.60 \\
\hline Time of A massecuite process (h) & 4.56 & 4.56 & 4.49 & 4.56 & 4.60 \\
\hline $\begin{array}{c}\text { Crystal mass percentage in A massecuite } \\
(\%)\end{array}$ & 51.13 & 55.75 & 51.33 & 48.49 & 51.28 \\
\hline MS before centrifugation (mm) & 0.59 & 0.62 & 0.62 & 0.61 & 0.62 \\
\hline $\mathrm{CV}$ before centrifugation $(\%)$ & 38.81 & 40.15 & 38.97 & 37.43 & 38.05 \\
\hline $\begin{array}{l}\text { Massecuite inflow in A centrifuges } \\
\qquad\left(\mathrm{m}^{3} / \mathrm{h}\right)\end{array}$ & 13.00 & 13.00 & 13.00 & 13.00 & 13.00 \\
\hline Sugar outflow in A centrifuges $\left(\mathrm{m}^{3} / \mathrm{h}\right)$ & 6.02 & 6.56 & 6.09 & 5.80 & 6.11 \\
\hline Sugar pol $(\%)$ & 97.82 & 98.10 & 97.86 & 97.71 & 97.88 \\
\hline MS after centrifugation (mm) & 0.64 & 0.66 & 0.66 & 0.65 & 0.66 \\
\hline CV after centrifugation $(\%)$ & 30.58 & 31.53 & 31.04 & 30.31 & 30.62 \\
\hline Molasses outflow in A centrifuges $\left(\mathrm{m}^{3} / \mathrm{h}\right)$ & 7.68 & 7.14 & 7.61 & 7.90 & 7.59 \\
\hline A molasses brix $(\%)$ & 75.67 & 76.13 & 75.76 & 75.75 & 75.89 \\
\hline A molasses purity $(\%)$ & 74.65 & 72.39 & 74.39 & 75.52 & 74.31 \\
\hline $\begin{array}{c}\text { Syrup consumption in A massecuite } \\
\text { process }\left(\mathrm{m}^{3}\right)\end{array}$ & 104 & 123 & 123 & 91 & 91 \\
\hline $\begin{array}{l}\text { Steam consumption in A massecuite } \\
\text { process }(\mathrm{t})\end{array}$ & 47 & 69 & 68 & 33 & 34 \\
\hline
\end{tabular}

syrup and steam flow rates were only adjusted in order to maintain supersaturation within the metastable zone limits according to the maximum volumes of each step. In simulations 3' and 4', the times of each step were altered so that the variables approximated their specifications.

Modification of the clarified syrup brix did not affect the crystal size distribution, but substantially altered the crystal mass percentage in the massecuite. Hence, the changes in sugar productions in simulations 3 and 4 were not related to fine crystal loss in the centrifugation, as occurred in the case of variations in the clarified syrup purity. Instead, they were related to an increase or decrease of the crystal concentration in the massecuite.

Reducing the tightening time by $4 \mathrm{~min}$ in simulation 3 ' and increasing it by $2.5 \mathrm{~min}$ in simulation 4' were sufficient to approximate the crystal mass concentration in the massecuite to the base simulation result. Consequently, the sugar production values in simulations 3' and 4' became similar to the sugar production in the base simulation.

Use of more diluted syrup in simulations 3 and 3 ' resulted in an increase of $18.3 \%$ in the syrup consumption and increases in steam consumption of $46.8 \%$ in simulation 3 and $44.7 \%$ in simulation $3^{\prime}$. In simulations 4 and 4', use of more concentrated syrup resulted in a $12.5 \%$ decrease in syrup consumption. The decreases in steam consumption in simulations 4 and 4' were 29.8 and $27.7 \%$, respectively.

In the industrial process, fluctuations in syrup brix reflect fluctuations in the juice and steam flow rates in the evaporation step. The period studied was characterized by high instabilities in cane processing and steam supply, due to mechanical problems in the mills and frequent shutdowns of the electric power generator. The sugar manufacturing sector accounts for a large fraction of the total steam consumption (Shamim et al., 2016), so the fluctuations cause large imbalances in other operations that also use the steam generated in the evaporators, such as juice heating and ethanol distillation.

Table 7 compares the results of the base simulation with the results of simulation 5 , in which the pressure of the steam used in the $\mathrm{A}$ and $\mathrm{B}$ vacuum pans was according to a sinusoidal function, in order to simulate the pressure fluctuations that occurred in the industrial process.

In this case, no variable was changed significantly. In simulation 5 , the steam pressure varied within the range from 1.42 to 1.70 bar, causing its vaporization enthalpy to vary from 2227.4 to $2211.9 \mathrm{~kJ} / \mathrm{kg}$, respectively. In other words, the fluctuation in steam vaporization enthalpy was at most $0.7 \%$, compared to the enthalpy in the base simulation, which was not sufficient to cause any significant change in the simulation results. In the industrial practice, the factor that actually affects the crystallization process is the steam flow rate available for this operation. Pressure gauges, rather than flow meters, are generally used in the steam lines, so a decrease in the steam flow rate is indicated by a pressure drop in the line.

In the base simulation, the steam flow rates were constant in each crystallization step and were percentages of the maximum possible flow rate $(8.8$ $\mathrm{kg} / \mathrm{s}$ ). The percentages were selected in order to maintain the supersaturation within the desired limits. In simulation 6, the maximum sinusoidal fluctuations in the maximum steam flow rate were imposed on the A and B massecuite processes, separately, such that the limits of the metastable zone continued to be respected.

For the A and B massecuite processes, the maximum amplitudes of the sinusoidal functions were 0.5 and $1.0 \mathrm{~kg} / \mathrm{s}$, respectively. The period of the functions was 
Table 7. Comparison of the results for the base simulation and for simulation 5, in which the steam pressure was according to a sinusoidal function, simulating the pressure fluctuations that occurred in the industrial process.

\begin{tabular}{ccc}
\hline & Base simulation & Simulation 5 \\
\hline Time of B massecuite process $(\mathrm{h})$ & 5.19 & 5.19 \\
Magma purity (\%) & 40.54 & 40.75 \\
Final molasses purity (\%) & 94.15 & 94.15 \\
Crystal mass percentage in B massecuite $(\%)$ & 59.58 & 59.58 \\
Steam consumption in B massecuite process $(\mathrm{t})$ & 47 & 47 \\
Time of A massecuite process $(\mathrm{h})$ & 4.56 & 4.56 \\
Crystal mass percentage in A massecuite $(\%)$ & 51.13 & 51.77 \\
Massecuite inflow in A centrifuges $\left(\mathrm{m}^{3} / \mathrm{h}\right)$ & 13.00 & 13.00 \\
Sugar outflow in A centrifuges $\left(\mathrm{m}^{3} / \mathrm{h}\right)$ & 6.02 & 6.02 \\
Sugar pol $(\%)$ & 97.82 & 97.82 \\
MS after centrifugation $(\mathrm{mm})$ & 0.64 & 0.64 \\
CV after centrifugation $(\%)$ & 30.58 & 30.69 \\
Molasses outflow in A centrifuges $\left(\mathrm{m}^{3} / \mathrm{h}\right)$ & 7.68 & 7.68 \\
A molasses brix $(\%)$ & 75.67 & 75.67 \\
A molasses purity $(\%)$ & 74.65 & 74.65
\end{tabular}

kept at $15 \mathrm{~min}$, the same as the period of the variation applied to the steam pressure in simulation 5. The crystallization steps maintained the percentages of the maximum steam flow rate used in the base simulation.

Figs. 6 and 7 show the sinusoidal functions applied to the maximum steam flow rates of the $\mathrm{A}$ and $\mathrm{B}$

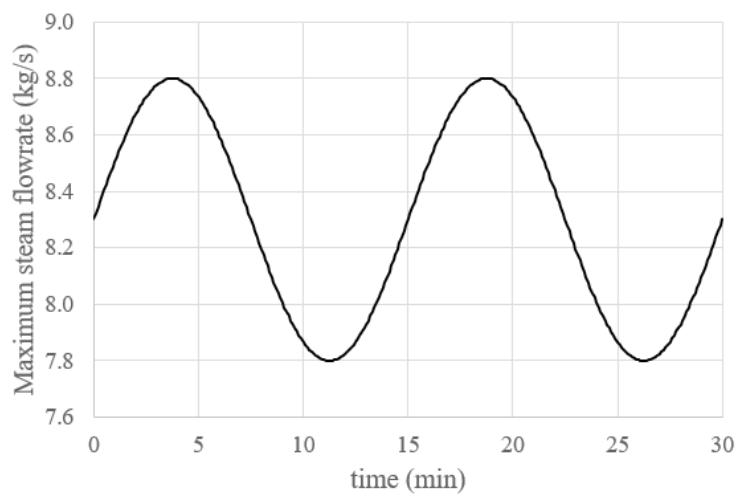

Figure 6. Fluctuation of the maximum steam flow rate in the A massecuite process. massecuite processes, respectively. In both functions, the maximum possible flow rate of $8.8 \mathrm{~kg} / \mathrm{s}$ was maintained, since it corresponded to the flow rate achieved with total opening of the steam valve.

Table 8 compares the results of the base simulation and simulation 6. The steam flow rate fluctuation

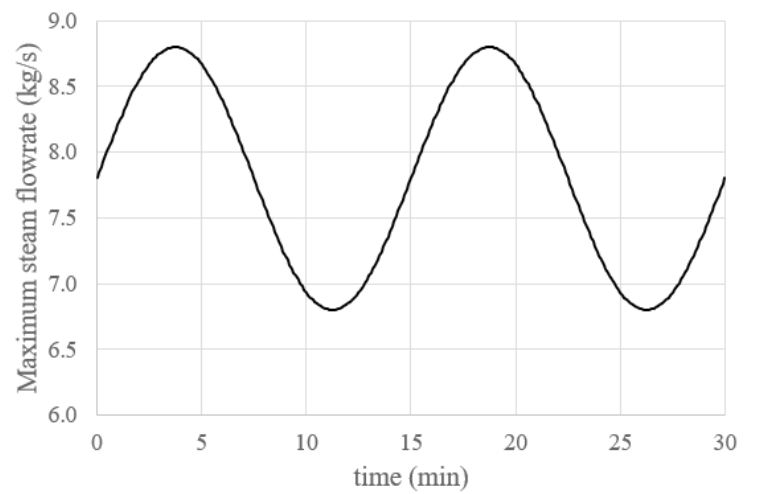

Figure 7. Fluctuation of the maximum steam flow rate in the B massecuite process.

Table 8. Comparison of the results for the base simulation and for simulation 6 , in which the maximum steam flow rates were replaced by the sinusoidal functions.

\begin{tabular}{ccc}
\hline & Base simulation & Simulation 6 \\
\hline Time of B massecuite process $(\mathrm{h})$ & 5.19 & 5.19 \\
Crystal mass percentage in B massecuite $(\%)$ & 40.54 & 34.22 \\
Magma purity (\%) & 94.15 & 93.54 \\
Final molasses purity $(\%)$ & 59.58 & 62.31 \\
Time of A massecuite process $(\mathrm{h})$ & 4.56 & 4.56 \\
Crystal mass percentage in A massecuite $(\%)$ & 51.13 & 40.97 \\
Massecuite inflow in A centrifuges $\left(\mathrm{m}^{3} / \mathrm{h}\right)$ & 13.00 & 13.00 \\
Sugar outflow in A centrifuges $\left(\mathrm{m}^{3} / \mathrm{h}\right)$ & 6.02 & 5.01 \\
Sugar pol $(\%)$ & 97.82 & 97.18 \\
MS after centrifugation $(\mathrm{mm})$ & 0.64 & 0.66 \\
CV after centrifugation $(\%)$ & 30.58 & 29.70 \\
Molasses outflow in A centrifuges $\left(\mathrm{m}^{3} / \mathrm{h}\right)$ & 7.68 & 8.68 \\
A molasses brix $(\%)$ & 75.67 & 75.24 \\
A molasses purity $(\%)$ & 74.65 & 78.22
\end{tabular}


affected the crystal mass percentages in the $\mathrm{A}$ and $\mathrm{B}$ massecuites. In the B massecuite process, it led to a decrease of magma purity and an increase of final molasses purity. In the A massecuite process, it caused a decrease in sugar outflow and increased the flow rate and purity of the A molasses. The crystal size distribution was not significantly altered.

\section{CONCLUSIONS}

A model was used to simulate sucrose crystallization, considering the balances of mass, energy, and population, together with the mechanisms of nucleation and growth rate dispersion. The model was able to satisfactorily represent the industrial two-massecuite system with A molasses recycling. The simulation results, including the crystal size distribution, were in good agreement with real data from the industrial process considered in this work. The comparison between simulated and real process data is limited to endpoint outcomes and not to the time progress of the whole crystallization process due to the lack of information of the real data during the process.

The use of modifications in the purity of the syrup used as the raw material for crystallization revealed that this variable exerted a strong influence on the crystal size distribution and consequently on fine crystal loss in the centrifugation step, leading to a major impact on the sugar production. Simulations of crystallization using low purity syrup resulted in crystal mean sizes below the desired specification, irrespective of attempts to change the duration times and flow rates of syrup and steam in the process steps.

On the other hand, the syrup brix did not have any substantial effect on the crystal size distribution, but had major impacts on steam consumption during crystallization and on the crystal mass percentage in the massecuite. The last effect could be easily corrected using small changes in tightening time, hence normalizing sugar production. However, the fluctuations in steam consumption during crystallization could negatively affect other industrial operations using the same steam, such as juice heating and ethanol distillation.

Variation of steam pressure did not in itself cause changes in the simulation results. Actually, the steam flow rate fluctuations affected the massecuite supersaturation and hence the crystallization rate.

\section{NOMENCLATURE}

$\mathrm{B}^{0} \quad$ Nucleation rate, $1 / \mathrm{s}$

BPE Boiling point elevation, ${ }^{\circ} \mathrm{C}$

bx Brix (mass percentage of dissolved solids), $\%$

$\mathrm{Cp} \quad$ Specific heat, $\mathrm{kJ} /\left(\mathrm{kg}^{\circ} \mathrm{C}\right)$
$\mathrm{C}_{\text {sat }} \quad$ Parameter for calculating impure solution supersaturation

CV Coefficient of variation, $\%$

$\mathrm{D}_{\mathrm{g}} \quad$ Growth rate dispersion, $\mathrm{m}^{2} / \mathrm{s}$

$\mathrm{F}^{\mathrm{g}} \quad$ Volumetric flow rate, $\mathrm{m}^{3} / \mathrm{h}$

G Linear crystal growth rate, $\mathrm{m} / \mathrm{s}$

$\mathrm{H} \quad$ Specific enthalpy, $\mathrm{kJ} / \mathrm{kg}$

$\mathrm{J}_{\text {cris }} \quad$ Crystal mass rate, $\mathrm{kg} / \mathrm{h}$

$\mathrm{J}$ Cris $\quad$ Vaporization rate, $\mathrm{kg} / \mathrm{h}$

$\mathrm{K}_{\mathrm{v}} \quad$ Experimental parameter of growth rate

$\mathrm{Kd}_{\mathrm{g}}^{\mathrm{g}} \quad$ Experimental parameter of growth rate dispersion

$\mathrm{K}_{\mathrm{n}} \quad$ Experimental parameter of nucleation rate

$\mathrm{k}_{\mathrm{v}}^{\mathrm{n}} \quad$ Crystal shape factor

$\mathrm{k}_{\text {vap }}$ Parameter for calculating vaporization rate, $\mathrm{kg} /\left(\mathrm{h}^{\circ} \mathrm{C}\right)$

L Crystal characteristic size, $m$

M Mass, $\mathrm{kg}$

MS Crystal mean size, $\mathrm{m}$

n Population density, $1 / \mathrm{m}$

N Number of crystals

P Pressure, bar

pur Purity (mass percentage of sucrose in dissolved solids), $\%$

Q Rate of heat, $\mathrm{kJ} / \mathrm{h}$

S Supersaturation

S* Critical supersaturation

SD Standard deviation, $\mathrm{m}$

$\mathrm{T} \quad$ Temperature, ${ }^{\circ} \mathrm{C}$

$\mathrm{V} \quad$ Volume, $\mathrm{m}^{3}$

W Mass flow rate, $\mathrm{kg} / \mathrm{h}$

\section{Greek letters}

$\alpha \quad$ Correction factor for heating steam enthalpy

$\beta \quad$ Efficiency of solid-liquid separation, \%

$\eta \quad$ Mass percentage of crystals remaining in solid stream, \%

$\mu_{i} \quad$ Distribution moment

$\rho \quad$ Density, $\mathrm{kg} / \mathrm{m}^{3}$

$\omega_{c} \quad$ Crystal mass percentage, $\%$

$\begin{array}{ll}\text { Subscripts } \\ \mathrm{c} & \text { Crystal } \\ \mathrm{i} & \text { Inflow } \\ \mathrm{imp} & \text { Impurity } \\ \mathrm{m} & \text { Massecuite } \\ \mathrm{mol} & \text { Molasses } \\ \mathrm{o} & \text { Outflow } \\ \text { sat } & \text { Saturation } \\ \text { sol } & \text { Solution } \\ \text { suc } & \text { Sucrose } \\ \text { sug } & \text { Sugar } \\ \text { susp } & \text { Suspension } \\ \mathrm{s}_{1} & \text { Heating steam } \\ \mathrm{s}_{2} & \text { Vapor generated in vacuum pans } \\ \text { vap } & \text { Vaporization } \\ \mathrm{w} & \text { Water }\end{array}$




\section{ACKNOWLEDGMENTS}

This work was supported by Fundação de Amparo à Pesquisa do Estado de São Paulo (FAPESP) [grant number 2011/51902-9] and by Conselho Nacional de Desenvolvimento Científico e Tecnológico (CNPq) [grant number 132045/2017-6].

\section{REFERENCES}

Chen, J.C.P., Chou, C.C. Cane sugar handbook: a manual for cane sugar manufacturers and their chemists, $12^{\text {th }}$ ed. John Wiley \& Sons, New York (1993).

Chorão, J.M.M.N. Operação assistida por computador de um cristalizador evaporativo industrial de açúcar. Ph.D. Thesis, Faculdade de Engenharia da Universidade do Porto (1995).

Dias, M.O.S., Maciel Filho, R., Mantelatto, P.E., Cavalett, O., Rossell, C.E.V., Bonomi, A., Leal, M.R.L.V. Sugarcane processing for ethanol and sugar in Brazil. Environmental Development, 15, 35-51 (2015). https://doi.org/10.1016/j.envdev.2015.03.004

Fernandes, A.C. Cálculos na agroindústria da cana-deaçúcar, $3^{\text {rd }}$ ed. STAB, Piracicaba (2011).

Georgieva, P., Meireles, M.J., Feyo de Azevedo, S. Knowledge-based hybrid modelling of a batch crystallisation when accounting for nucleation, growth and agglomeration phenomena. Chemical Engineering Science, 58, 3699-3713 (2003). https://doi.org/10.1016/S0009-2509(03)00260-4

Gonzales, P.E.M., Andrade, C.M.G. Modelagem do processo de cristalização da sacarose no cozimento de massa A. III Simpósio Paranaense de Modelagem, Simulação e Controle de Processos - SIMPROC. Curitiba (2018). https://doi. org/10.5380/19847521.3simproc2018.a05p31-38

Howell, T.A., Ben-Yoseph, E., Rao, C., Hartel, R.W. Sucrose crystallization kinetics in thin films at elevated temperatures and supersaturations. Crystal Growth \& Design, 2, 67-72 (2002). https://doi. org $/ 10.1021 / \operatorname{cg} 015551 \mathrm{v}$

Hugot, É. Handbook of cane sugar engineering, $3^{\text {rd }}$ ed. Elsevier, Amsterdam (1986).

ICUMSA, ICUMSA Methods Book. ICUMSA, England (2015).

Jesus, C.D.F. Validação da simulação dinâmica das etapas de evaporação e cristalização da produção de açúcar com dados obtidos em plantas industriais. $\mathrm{Ph} . \mathrm{D}$. Thesis, Universidade Federal de São Carlos (2004).

Khaddour, I.A., Bento, L.S.M., Ferreira, A.M.A., Rocha, F.A.N. Kinetics and thermodynamics of sucrose crystallization from pure solution at different initial supersaturations. Surface Science, 604, 1208-1214 (2010). https://doi.org/10.1016/j. susc. 2010.04 .005
Kumar, K.V., Martins, P., Rocha, F. Modelling of the batch sucrose crystallization kinetics using artificial neural networks: comparison with conventional regression analysis. Industrial \& Engineering Chemistry Research, 47, 4917-4923 (2008). https:// doi.org/10.1021/ie701706v

Liang, B., Hartel, R.W. Techniques for developing nucleation and growth kinetics from MSMPR data for sucrose crystallization in the presence of growth rate dispersion. Journal of Crystal Growth, 108, 129-142 (1991). https://doi.org/10.1016/00220248(91)90361-8

Lopes, C.H., Borges, M.T.M.R. Manual de análise de açúcar: açúcar VHP, VVHP, demerara, cristal, refinado e açúcar líquido. Sucral, Araras (2004).

Martins, P.M., Rocha, F.A., Rein, P. Modeling sucrose evaporative crystallization, Part 2, Investigation into crystal growth kinetics and solubility. Industrial \& Engineering Chemistry Research, 44, 8865-8872 (2005). https://doi.org/10.1021/ie050731d

Mazaeda, R., Acebes, L.F., Rodríguez, A., Engell, S., Prada, C., Sugar crystallization benchmark. Computer Aided Chemical Engineering, 33, 613618 (2014). https://doi.org/10.1016/B978-0-44463456-6.50103-4

Merheb, G.A. Influência da contaminação combinada de dextrana e amido na cristalização do açúcar. Ph.D. Thesis, Universidade Federal de São Carlos (2014).

Mersmann, A. Crystallization technology handbook, $2^{\text {nd }}$ ed. Marcel Dekker, New York (2001). https:// doi.org/10.1201/9780203908280

Mullin, J.W. Crystallization, $4^{\text {th }}$ ed. Butterworth Heinemann, Woburn (2001). https://doi. org/10.1016/B978-075064833-2/50009-7

Oliveira, D.T., Esquiaveto, M.M.M., Silva Júnior, J.F. Impacto dos itens da especificação do açúcar na indústria alimentícia. Ciência e Tecnologia de Alimentos, 27, 99-102 (2007). https://doi. org/10.1590/S0101-20612007000500018

Ouiazzane, S., Messnaoui, B., Abderafi, S., Wouters, J., Bounahmidi, T. Modeling of sucrose crystallization kinetics: the influence of glucose and fructose. Journal of Crystal Growth, 310, 3498-3503 (2008a). https://doi.org/10.1016/j.jcrysgro.2008.04.042

Ouiazzane, S., Messnaoui, B., Abderafi, S., Wouters, J., Bounahmidi, T. Estimation of sucrose crystallization kinetics from batch crystallizer data. Journal of Crystal Growth 310, 798-803 (2008b). https://doi.org/10.1016/j.jcrysgro.2007.11.179

Payne, J.H. Operações unitárias na produção de açúcar de cana. Nobel, São Paulo (1989).

Rodrigues, R., Soares, R.P., Secchi, A.R. Teaching chemical reaction engineering using EMSO simulator. Computer Applications in Engineering Education, 18, 607-618 (2010). https://doi. org/10.1002/cae.20255 
Schlumbach, K., Pautov, A., Flöter, E. Crystallization and analysis of beet and cane sugar blends. Journal of Food Engineering, 196, 159-169 (2017). https:// doi.org/10.1016/j.jfoodeng.2016.10.026

Shamim, F., Hernández, R., Paulen, R., Engell, S. A hierarchical coordination approach to the optimal operation of a sugar crystallization process. Computer Aided Chemical Engineering, 38, 703708 (2016). https://doi.org/10.1016/B978-0-44463428-3.50122-3

Soares, R.P., Secchi, A.R. EMSO: A new environment for modelling, simulation and optimization. Computer Aided Chemical Engineering, 14, 947-952 (2003). https://doi.org/10.1016/S15707946(03)80239-0

Soares, R.P., Secchi, A.R. Modifications, simplifications, and efficiency tests for the CAPEOPEN numerical open interfaces. Computers \& Chemical Engineering, 28, 1611-1621 (2004).

Sousa, J.S.I., Peixoto, A.M., Toledo, F.F. Enciclopédia agrícola brasileira. Editora da Universidade de São Paulo, ESALQ, São Paulo (1995).

Van Hook, A. Kinetics of sucrose crystallization: real massecuites. Industrial \& Engineering Chemistry, 40, 85-89 (1948). https://doi.org/10.1021/ ie $50457 \mathrm{a} 025$

Van Hook, A. Kinetics of sucrose crystallization: sucrose-nonsucrose solutions. Industrial \& Engineering Chemistry, 38, 50-53 (1946). https:// doi.org/10.1021/ie50433a027

Van Hook, A. Kinetics of sucrose crystallization: mechanism of reaction. Industrial \& Engineering Chemistry, 37, 782-785 (1945). https://doi. org/10.1021/ie50428a028

Van Hook, A. Kinetics of sucrose crystallization: pure sucrose solutions. Industrial \& Engineering Chemistry, 36, 1042-1047 (1944). https://doi. org/10.1021/ie50419a018

Zagrodzki, S., Zaorska, H. Influence of the decolorization of sugar juices and products on the crystallization rate in impure solutions. International Sugar Journal, 76, 300-303, 337-338 (1974).

Zaorska, H. Changes in sucrose crystallization rate as a function of the quantity of colouring matter in the solution. International Sugar Journal, 70, 99-103 (1968).

\section{APPENDIX}

A. Model equations and correlations for physical properties.

A.1. Solution/suspension

- Mass of solution (kg):

$\mathrm{M}_{\mathrm{sol}}=\mathrm{M}_{\mathrm{suc}}+\mathrm{M}_{\mathrm{imp}}+\mathrm{M}_{\mathrm{w}}$
- Solution brix (\%):

$$
\mathrm{bx}_{\mathrm{sol}}=\left(\frac{\mathrm{M}_{\mathrm{suc}}+\mathrm{M}_{\mathrm{imp}}}{\mathrm{M}_{\mathrm{sol}}}\right) \cdot 100
$$

- Solution purity (\%):

$$
\operatorname{pur}_{\mathrm{sol}}=\left(\frac{\mathrm{M}_{\mathrm{suc}}}{\mathrm{M}_{\mathrm{suc}}+\mathrm{M}_{\mathrm{imp}}}\right) \cdot 100
$$

- Specific heat of solution $\left(\mathrm{kJ} /\left(\mathrm{kg}^{\circ} \mathrm{C}\right)\right)$ :

$\mathrm{Cp}_{\mathrm{sol}}=\frac{4186.8-29.7 \cdot \mathrm{bx}_{\mathrm{sol}}+4.61 \cdot \mathrm{bx}_{\mathrm{sol}} \cdot \frac{\mathrm{pur}_{\mathrm{sol}}}{100}+0.075 \cdot \mathrm{bx}_{\mathrm{sol}} \cdot \mathrm{T}}{1000}$

- Specific enthalpy of solution $(\mathrm{kJ} / \mathrm{kg})$ :

$\mathrm{H}_{\mathrm{sol}}=\mathrm{Cp}_{\mathrm{sol}} \cdot \mathrm{T}$

- Suspension volume $\left(\mathrm{m}^{3}\right)$ :

$\mathrm{V}_{\text {susp }}=\frac{\mathrm{M}_{\text {sol }}}{\rho_{\mathrm{sol}}}+\frac{\mathrm{M}_{\mathrm{c}}}{\rho_{\mathrm{c}}}$

- Boiling point elevation $\left({ }^{\circ} \mathrm{C}\right)$ :

$\mathrm{BPE}=\left(0.03-0.018 \cdot \frac{\mathrm{pur}_{\mathrm{sol}}}{100}\right) \cdot\left(\mathrm{T}_{\mathrm{sat}}+84\right) \cdot\left(\frac{\mathrm{bx}_{\mathrm{sol}}}{100-\mathrm{bx}_{\mathrm{sol}}}\right)$

- Density of pure solution $\left(\mathrm{kg} / \mathrm{m}^{3}\right)$ :

$\rho_{\mathrm{sol}}=\left(1000+\frac{\mathrm{bx}_{\mathrm{sol}} \cdot\left(200+\mathrm{bx}_{\mathrm{sol}}\right)}{54}\right) \cdot\left(1-0.036 \cdot \frac{\mathrm{T}-20}{160-\mathrm{T}}\right)$

- Density of impure solution $\left(\mathrm{kg} / \mathrm{m}^{3}\right)$ :

$\rho_{\text {sol }}=\rho_{\text {sol }}+1000 \cdot\left\{-1+\exp \left[\left(-6.927 .10^{-6} \cdot \mathrm{bx}_{\mathrm{sol}}^{2}-1.164 .10^{-4} \cdot \mathrm{bx}_{\mathrm{sol}}\right) \cdot\left(\frac{\mathrm{pur}_{\mathrm{sol}}}{100}-1\right)\right]\right\}$

- Density of suspension $\left(\mathrm{kg} / \mathrm{m}^{3}\right)$ :

$\rho_{\text {susp }}=\frac{\rho_{\text {sol }} \cdot \rho_{c}}{\rho_{c}-\frac{\omega_{c}}{100} \cdot\left(\rho_{c}-\rho_{\text {sol }}\right)}$

- Crystal mass percentage (\%):

$\omega_{\mathrm{c}}=\frac{\mathrm{M}_{\mathrm{c}}}{\mathrm{M}_{\mathrm{sol}}+\mathrm{M}_{\mathrm{c}}}$

- Saturation brix (\%):

$$
\begin{aligned}
\mathrm{bx}_{\mathrm{sat}} & =64.447+8.222 .10^{-2} \cdot \mathrm{T}+1.66169 .10^{-3} \cdot \mathrm{T}^{2}- \\
& -1.558 .10^{-6} \cdot \mathrm{T}^{3}-4.63 .10^{-8} \cdot \mathrm{T}^{4}
\end{aligned}
$$


- Supersaturation:

$$
\begin{aligned}
\mathrm{S}=\frac{\mathrm{bx}_{\mathrm{sol}} /\left(100-\mathrm{bx}_{\mathrm{sol}}\right)}{\left(\mathrm{bx}_{\mathrm{sat}} \cdot \mathrm{C}_{\mathrm{sat}}\right) /\left(100-\mathrm{bx}_{\mathrm{sat}}\right)} \\
\mathrm{C}_{\mathrm{sat}}=0.1 \cdot \frac{\mathrm{bx}_{\mathrm{sol}}}{100-\mathrm{bx}_{\mathrm{sol}}} \cdot\left(1-\frac{\mathrm{pur}_{\mathrm{sol}}}{100}\right)+0.4+0.6 . \\
\cdot \exp \left[-0.24 \cdot \frac{\mathrm{bx}_{\mathrm{sol}}}{100-\mathrm{bx}_{\mathrm{sol}}} \cdot\left(1-\frac{\mathrm{pur}_{\mathrm{sol}}}{100}\right)\right]
\end{aligned}
$$

- Critical supersaturation:

$$
\begin{aligned}
\mathrm{S}^{*} & =1.129-0.284 \cdot\left(1-\frac{\mathrm{pur}_{\mathrm{sol}}}{100}\right)+ \\
& +[2.333-0.0709 \cdot(\mathrm{T}-60)] \cdot\left(1-\frac{\mathrm{pur}_{\mathrm{sol}}}{100}\right)^{2}
\end{aligned}
$$

\section{A.2. Crystals}

- Specific heat of crystals $\left(\mathrm{kJ} /\left(\mathrm{kg}^{\circ} \mathrm{C}\right)\right)$ :

$\mathrm{Cp}_{\mathrm{c}}=\frac{1163.2+3.488 \cdot \mathrm{T}}{1000}$

- Specific enthalpy of crystals $(\mathrm{kJ} / \mathrm{kg})$ :

$$
\mathrm{H}_{\mathrm{c}}=\mathrm{Cp}_{\mathrm{c}} \cdot \mathrm{T}
$$

- Crystal volume, $\mathrm{m}^{3}$ :

$\mathrm{V}_{\mathrm{c}}=\frac{\mathrm{M}_{\mathrm{c}}}{\rho_{\mathrm{c}}}$

- Mean size, m:

$\mathrm{MS}=\frac{\mu_{4}}{\mu_{3}}$

- Coefficient of variation, $\%$ :

$\mathrm{CV}=\left(\sqrt{\frac{\mu_{3} \cdot \mu_{5}}{\mu_{4}^{2}}-1}\right) \cdot 100$
- Standard deviation, $\mathrm{m}$ :

$\mathrm{SD}=\frac{\mathrm{MS} \cdot \mathrm{CV}}{100}$

A.3. Water

- Water density $\left(\mathrm{kg} / \mathrm{m}^{3}\right)$ :

$\rho_{\mathrm{w}}=1016.7-0.57 \cdot \mathrm{T}$

- Specific heat of water $\left(\mathrm{kJ} /\left(\mathrm{kg}^{\circ} \mathrm{C}\right)\right)$ :

$\mathrm{Cp}_{\mathrm{w}}=4.18 \cdot\left(1.0017-1.5754 .10^{-4} \cdot \mathrm{T}\right)+2.107 .10^{-6} \cdot \mathrm{T}^{2}$

- Specific enthalpy of water $(\mathrm{kJ} / \mathrm{kg})$ :

$\mathrm{H}_{\mathrm{w}}=\mathrm{Cp}_{\mathrm{w}} \cdot \mathrm{T}$

- Specific vaporization enthalpy of water $(\mathrm{kJ} / \mathrm{kg})$ :

$0.1<\mathrm{P}<1$

$\Delta \mathrm{H}_{\text {vap }}=\frac{2263280-58210 \cdot \ln (\mathrm{P})}{1000}$

$$
1<\mathrm{P}<3
$$

$\Delta \mathrm{H}_{\text {vap }}=\frac{2257510-85950 \cdot \ln (\mathrm{P})}{1000}$

- Saturation temperature of water $\left({ }^{\circ} \mathrm{C}\right)$ :

$0.1<\mathrm{P}<1^{-}$

$$
\mathrm{T}_{\text {sat }}=122.551 \cdot \exp (-0.246 \cdot \mathrm{P}) \cdot \mathrm{P}^{0.413}
$$

$$
1<\mathrm{P}<3
$$

$\mathrm{T}_{\text {sat }}=100.884 \cdot \exp \left(-1.203 .10^{-2} \cdot \mathrm{P}\right) \cdot \mathrm{P}^{0.288}$

A.4. Steam

- Specific enthalpy of steam $(\mathrm{kJ} / \mathrm{kg})$ : 
